\title{
The Dynamic Ligand Field of a Molecular Qubit: Decoherence Through Spin-Phonon Coupling
}

Ruben Mirzoyan and Ryan G. Hadt*

Division of Chemistry and Chemical Engineering, Arthur Amos Noyes Laboratory of Chemical Physics, California Institute of Technology, Pasadena, California 91125, United States

Corresponding Author: rghadt@,caltech.edu

\begin{abstract}
Quantum coherence of $S=1 / 2$ transition metal-based quantum bits (qubits) is strongly influenced by the magnitude of spin-phonon coupling. While this coupling is recognized as deriving from dynamic distortions about the first coordination sphere of the metal, a general model for understanding and quantifying ligand field contributions has not been established. Here we derive a general ligand field theory model to describe and quantify the nature of spin-phonon coupling terms in $\mathrm{S}=1 / 2$ transition metal complexes. We show that the coupling term for a given vibrational mode is governed by: 1) the magnitude of the metal-based spin-orbit coupling constant, 2) the magnitude and gradient in the ligand field excited state energy, and 3) dynamic relativistic nephelauxetic contributions reflecting the magnitude and gradient in the covalency of the ligandmetal bonds. From an extensive series of density functional theory (DFT) and time-dependent DFT (TDDFT) calculations calibrated to a range of experimental data, spin-phonon coupling terms describing minimalistic $D_{4 h} / D_{2 d}\left[\mathrm{CuCl}_{4}\right]^{2-}$ and $C_{4 v}\left[\mathrm{VOCl}_{4}\right]^{2-}$ complexes translate to and correlate with experimental quantum coherence properties observed for $\mathrm{Cu}(\mathrm{II})$ - and $\mathrm{V}$ (IV)-based molecular qubits with different ligand sets, geometries, and coordination numbers. While providing a fundamental framework and means to benchmark current qubits, the model and methodology described herein can be used to screen any $S=1 / 2$ molecular qubit candidate and guide the discovery of room temperature coherent materials for quantum information processing.
\end{abstract}




\section{Introduction.}

The coupling of electron spin to phonons/vibrations plays important roles in the dynamical properties of transition metal complexes and materials. For example, spin-phonon coupling plays a major role in the photophysical and photochemical properties of transition metal complexes, including ultrafast spin state switching and intersystem crossing, wherein it provides a strong influence on nonequilibrium dynamics. ${ }^{1-5}$ It is also a major factor in the magnetization dynamics of single molecule magnets ${ }^{6-9}$ and coherent materials for quantum information science. ${ }^{10-16}$ Beyond molecular systems, spin-phonon coupling also plays important roles in extended solids and condensed matter (e.g., transition metal oxides) by giving rise to emergent phenomena such as colossal magnetoresistance and high $T_{C}$ superconductivity, ${ }^{17-22}$ including vibrational or optical control of these properties. ${ }^{23-26}$ Thus, fundamental studies of spin-phonon coupling can provide insights into a variety of research areas, and there are fascinating intersections between the nature of spin-phonon coupling in molecular systems (e.g., mononuclear, binuclear, and multinuclear transition metal complexes) and extended solids to be explored.

Recent research has focused on the use of $S=1 / 2$ transition metal complexes as quantum bits (qubits), as the magnetic field split electron spin sublevels $\left(M_{s}= \pm 1 / 2\right)$ provide a two-level system in which a coherent superposition state can be formed. This coherent superposition state, often initiated with a well-defined microwave pulse sequence in an electron paramagnetic resonance (EPR) spectrometer ( $\sim 9$ or $35 \mathrm{GHz}$ for X- or Q-band, respectively), can be leveraged to satisfy DiVincenzo's criteria for the physical implementation of a quantum computer. ${ }^{27}$ However, the lifetime of this state must be significantly longer than the gate operation time, and a significant challenge in the domain of molecular qubits is to understand the principles controlling coherence lifetimes. This understanding can then be leveraged for the synthetic design of new transition metal complexes with long-lived coherent states.

The quantities of measure to gauge different complexes are the spin-lattice relaxation time, $T_{1}$, the spin-spin lattice relaxation time, $T_{2}$, and the phase memory time, $T_{m}$, which serves as an "effective" $T_{2}$ often measured instead. Recent work has demonstrated the remarkable increase in $T_{2}$ when minimizing the quantity of nuclear spins in the environment of the complex, inclusive of both solvent and the ligand set. ${ }^{28}$ In these nuclear spin-free environments, $T_{1}$ has proved to be the upper bound to coherence lifetimes, which further motivates efforts to better understand contributions to $T_{1}$, including the role of the geometric and electronic structure of the transition 
metal complex. ${ }^{28-44}$ Recent works in this area by Sessoli et al. ${ }^{13,44}$, Coronado et al. ${ }^{14,15}$, and Freedman et al. ${ }^{33}$ have highlighted specific ligand field contributions to spin-phonon coupling and coherence dynamics. Additionally, $T_{l}$ relaxation times will also play a major role when molecular qubits are entangled in dimers, ${ }^{45-49}$ higher order complexes, or spin-dense arrays, ${ }^{36}$ which will be required for the realization of quantum computing applications.

While progress has been made experimentally in elongating $T_{1}$ and $T_{m}$ relaxation times of transition metal complexes at low temperatures $(<80 \mathrm{~K})$, very few metal complexes exhibit coherence properties up to room temperature. For example, vanadyl phthalocyanine (VOPc) diluted in a diamagnetic titanyl matrix exhibits room temperature coherence with a $T_{m}$ of $\sim 1 \mu$ s at $300 \mathrm{~K}$, even in the presence of a nuclear spin containing environment. ${ }^{37}$ Spin echoes have also been observed up to room temperature in the benzene-1,2-dithiolate (bdt) ligated $\left(\mathrm{Ph}_{4} \mathrm{P}\right)_{2}\left[\mathrm{Cu}\left(\mathrm{C}_{6} \mathrm{H}_{4} \mathrm{~S}_{2}\right)_{2}\right]^{33} \quad\left(\mathrm{Cu}(\mathrm{bdt})_{2}\right)$ and the maleonitriledithiolate (mnt) ligated $\left(\mathrm{Ph}_{4} \mathrm{P}\right)_{2}\left[\mathrm{Cu}(\mathrm{mnt})_{2}\right]^{50}\left(\mathrm{Cu}(\mathrm{mnt})_{2}\right)$ complexes diluted in diamagnetic $\mathrm{Ni}$ lattices. At lower temperatures $(\sim 80 \mathrm{~K})$, relaxation is dominated by the direct, Raman, and Orbach mechanisms, while a mechanism involving spin-phonon coupling and the modulation of the energy gap between the $\mathrm{M}_{\mathrm{s}}= \pm 1 / 2$ sublevels dominates at higher temperatures. ${ }^{51,52}$ Thus, in order to achieve room temperature coherent materials, spin-phonon coupling and its contribution to $T_{1}$ must be better understood. Doing so will allow for direct manipulation of geometric and electronic structure to overcome this barrier. Furthermore, while achieving room temperature coherence is of great technological interest for quantum information processing, these room temperature coherent materials will also provide exciting opportunities for the fundamental studies of spin-phonon coupling and will complement studies of single molecule magnets and photoactive transition metal complexes.

Many of the highest performing $S=1 / 2$ qubit candidates feature similar structural motifs: 1) a four coordinate square planar $\mathrm{Cu}(\mathrm{II})$, or 2) a four coordinate vanadyl moiety featuring a triple bond between the V(IV) and oxo ligand. Comparisons between 1) and 2) and six coordinate, pseudo $O_{h} \mathrm{~V}(\mathrm{IV})$ complexes have also been made to highlight structural and electronic contributions to $T_{1}{ }^{13,33,53}$ As shown below, multiple contributions need to be accounted for in order to make direct comparisons between $S=1 / 2$ molecular qubits and thus to understand the origins of their coherence times. 
Given coherent superposition states are generated within the $\mathrm{M}_{\mathrm{S}}= \pm 1 / 2$ sublevels of a metal complex, coherence properties are expected to be influenced by the same contributions governing g-values. Ligand field theory (LFT) has provided expressions for understanding geometric and electronic structure contributions to the g-values of $\mathrm{Cu}(\mathrm{II})$ complexes. ${ }^{54}$ Here this model is extended more generally to a dynamic regime, which allows for the direct understanding of spinphonon coupling contributions to the g-values of $S=1 / 2$ transition metal complexes. Using the ORCA program, ${ }^{55,56}$ the LFT expressions are further supported by a range of spectroscopically calibrated density functional theory (DFT) and time-dependent DFT (TDDFT) calculations on the well-studied $D_{4 h}$ and $D_{2 d}\left[\mathrm{CuCl}_{4}\right]^{2-}$ and $C_{4 v}\left[\mathrm{VOCl}_{4}\right]^{2-} .57,58$ The correlations between experiment and LFT, DFT, and TDDFT calculations have elucidated the key factors that contribute to the nature of spin-phonon coupling terms in $S=1 / 2$ transition metal complexes, thus providing a detailed orbital and bonding picture for the first time. The model presented here indicates spinphonon coupling terms are governed by the magnitude of the metal-based spin-orbit coupling (SOC) constant, excited state mixing of orbital angular momentum into the ground state, and dynamic relativistic nephelauxetic contributions. The latter contribution is directly related to the covalencies of ligand-metal bonds and can modify the metal-based SOC constant from that of the free ion in a dynamic manner. Also, correlations between dynamic ground state orbital angular momentum and excited state coupling terms and their relations to spin-phonon coupling terms are drawn for the first time. Specific group theoretical correlations between high and lower symmetry point groups further provide a means to evaluate spin-phonon coupling terms across transition metal complexes and molecular qubits featuring different ligand sets, geometries, and coordination numbers. The model is in excellent agreement with a wide range of experimental quantum coherence properties of $\mathrm{Cu}(\mathrm{II})$ - and $\mathrm{V}(\mathrm{IV})$-based molecular qubits and therefore provides a means to rapidly evaluate spin-phonon coupling terms in any $S=1 / 2$ transition metal complex, including new qubit candidates.

\section{Results.}

\subsection{Dynamic Ligand Field Theory of $\mathrm{Cu}(\mathrm{II})$ g-values.}

$D_{4 h}\left[\mathrm{CuCl}_{4}\right]^{2-}$ has a ${ }^{2} \mathrm{~B}_{1 \mathrm{~g}}\left(\mathrm{x}^{2}-\mathrm{y}^{2}\right)$ ground state (Figure 1). In the absence of SOC, the ${ }^{2} \mathrm{~B}_{1 \mathrm{~g}}$ ground state contains no orbital angular momentum and thus would exhibit a g-value of 2.0023 (e.g., ge of the free electron) in the presence of a magnetic field. However, SOC provides a means for 
excited states to mix into the ${ }^{2} \mathrm{~B}_{1 \mathrm{~g}}$ ground state and thus introduce orbital angular momentum. This is shown in Figure 1 for $D_{4 h}\left[\mathrm{CuCl}_{4}\right]^{2-}$. Including SOC, the ${ }^{2} \mathrm{~B}_{1 \mathrm{~g}}$ ground state $\left(\Gamma_{7}\right)$ can mix with both the ${ }^{2} \mathrm{~B}_{2 \mathrm{~g}}\left(\Gamma_{7}\right)$ and ${ }^{2} \mathrm{E}_{\mathrm{g}}\left(\Gamma_{6}+\Gamma_{7}\right)$ excited states (Figure 1). From first order perturbation theory, the ground state reflecting the contributions of excited state SOC is: ${ }^{54}$

$$
\left|{ }^{2} B_{1 g}^{\prime}\right\rangle=\left|x^{2}-y^{2}\right\rangle-\frac{\lambda\left\langle x^{2}-y^{2}|\boldsymbol{L} \cdot \boldsymbol{S}| x y\right\rangle}{E_{B_{2 g}}}|x y\rangle-\frac{\lambda\left\langle x^{2}-y^{2}|\boldsymbol{L} \cdot \boldsymbol{S}| x z, y z\right\rangle}{E_{E_{g}}}|x z, y z\rangle
$$

(equation 1)

where $\lambda= \pm \zeta / 2 \mathrm{~S}\left(-830 \mathrm{~cm}^{-1}\right.$ for $\left.\mathrm{Cu}(\mathrm{II})\right), \boldsymbol{L}$ and $\boldsymbol{S}$ are the total orbital and spin angular momentum operators, respectively, and $E_{B_{2 g}}$ and $E_{E_{g}}$ are the energies of the ${ }^{2} \mathrm{~B}_{2 g}$ and ${ }^{2} \mathrm{E}_{g}$ excited states, respectively. ${ }^{54}$ For greater or less than half-filled electron configurations, either the negative or positive components of $\pm \zeta$ are used, respectively.

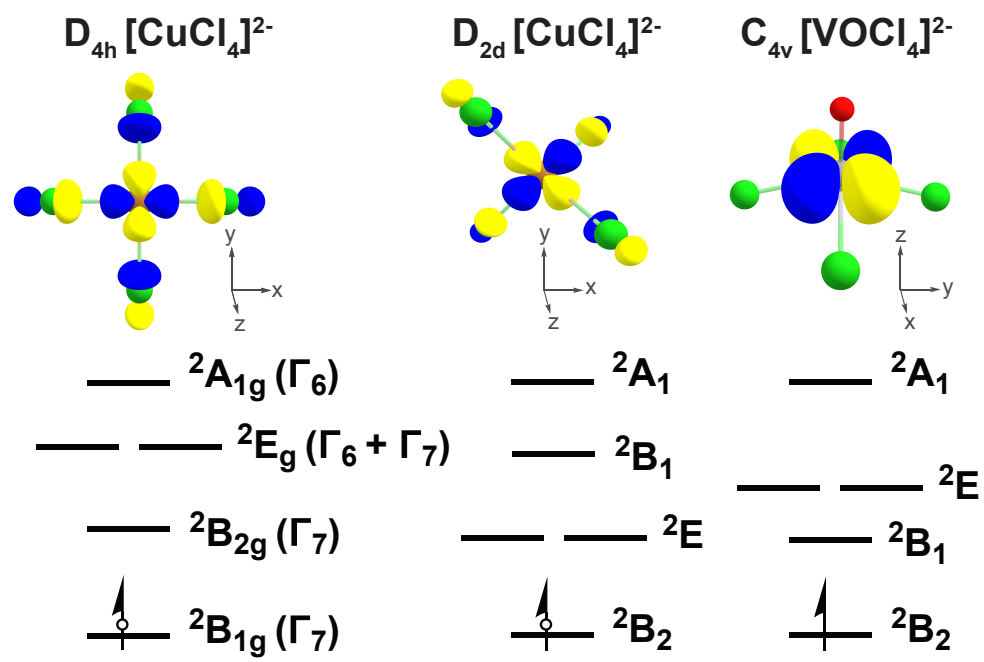

Figure 1. $\beta$-LUMOs and qualitative excited state energy diagrams for transition metal complexes considered in the Results sections. The hole formalism is used for $\left[\mathrm{CuCl}_{4}\right]^{2-}$, with $\mathrm{SOC}$ symmetries given for $D_{4 h}$.

An applied magnetic field will project out different components of $\boldsymbol{L}$ (e.g., $\boldsymbol{L}_{\boldsymbol{x}, \boldsymbol{y}, \boldsymbol{z}}$ ). Consequently, the magnitude of orbital angular momentum mixing into the ground state is anisotropic. The resulting perturbed ground state wavefunction can be modified to include covalent 
ligand-metal interactions. For $\mathrm{H} \| \mathrm{z}$ and taking the covalency of the $\mathrm{b}_{1 \mathrm{~g}}$ and $\mathrm{b}_{2 \mathrm{~g}}$ orbitals into account, the expression for $\mathrm{g}_{\|}\left(\mathrm{g}_{\mathrm{z}}\right)$ becomes: ${ }^{54}$

$$
g_{\|}=g_{e}-\frac{8 \lambda \alpha_{1}^{2} \beta_{1}^{2}}{E_{B_{2} g}}
$$

(equation 2)

where $\alpha_{1}$ and $\beta_{1}$ are the coefficients reflecting the amount of $\mathrm{d}(\mathrm{xy})$ and $\mathrm{d}\left(\mathrm{x}^{2}-\mathrm{y}^{2}\right)$ character, respectively. With $\mathrm{H} \| \mathrm{x}, \mathrm{y}$ and considering covalent interactions, equation 2 for $\mathrm{g}_{\perp}$ becomes:

$$
g_{\perp}=g_{e}-\frac{2 \lambda \gamma_{1}^{2} \beta_{1}^{2}}{E_{E_{g}}}
$$

(equation 3)

where $\gamma_{1}$ is the coefficient reflecting the $\mathrm{d}(\mathrm{xz}, \mathrm{yz})$ orbital contribution. From equations 2 and 3 , increasing the covalency of the ligand-metal bonds will decrease the deviation from 2.0023 through a relativistic nephelauxetic effect. ${ }^{59}$

The splitting between the ground state $\mathrm{M}_{\mathrm{s}}= \pm 1 / 2$ sublevels and the resulting coherent superposition lifetime is thus sensitive to dynamic behavior of the ligand field excited states and the covalencies of ligand-metal bonds. Fluctuations in the energy gap of a two-level system result in decoherence, and a coherence lifetime has been previously related to the variance in the energy gap by an inverse square root dependence. ${ }^{60}$ As the $g_{z}$-value and the $M_{s}= \pm 1 / 2$ energy gap are directly proportional to one another, the variance in the energy gap can be monitored by proxy of the g-value. Therefore, a descriptor to reflect such fluctuations is the variance in $\mathrm{g}_{z}$ (equation 5). To describe the $M$ vibrational modes denoted by $Q_{i}$, we separate the total harmonic vibrational wave function, $\Psi_{v i b}$, as a product of harmonic vibrational wave functions of each mode, $\Psi_{i}$, with the vibrational quantum numbers $N=\left\{n_{1}, \ldots, n_{R}\right\}$.

(equation 4)

$$
\Psi_{v i b}^{\mathrm{N}}\left(Q_{1}, \ldots, Q_{R}\right)=\prod_{i=1}^{M} \Psi_{\mathrm{i}}^{n_{i}}\left(Q_{i}\right)
$$


The variance in $g_{z}$ can then be expressed as:

$$
\operatorname{Var}\left[g_{z}\right]=\left\langle g_{z}^{2}\right\rangle-\left\langle g_{z}\right\rangle^{2} \approx \frac{\hbar}{2 \pi} \sum_{k=1}^{R}\left(\frac{\partial g_{z}}{\partial Q_{i}}\right)_{e}^{2}\left(n_{i}+\frac{1}{2}\right)\left(\frac{1}{v_{i} m_{i}}\right)+\frac{\hbar}{4 \pi} \sum_{k=1}^{R}\left(\frac{\partial^{2} g_{z}}{\partial Q_{i}^{2}}\right)_{e}^{2}\left(n_{i}^{2}+n_{i}+\frac{1}{4}\right)\left(\frac{1}{v_{i}^{2} m_{i}^{2}}\right)
$$

(equation 5).

In equation $5,\left(\frac{\partial g_{z}}{\partial Q_{i}}\right)$ and $\left(\frac{\partial^{2} g_{z}}{\partial Q_{i}^{2}}\right)$ are the equilibrium values of $\frac{\partial g_{z}}{\partial Q_{i}}$ and $\frac{\partial^{2} g_{z}}{\partial Q_{i}^{2}}$ when $Q_{i}=0$, respectively, $v_{i}$ are the harmonic frequencies, and $m_{i}$ are the reduced masses. To simplify the treatment of $\mathrm{g}_{\mathrm{z}}$, which depends on the position along a vibrational coordinate $Q_{i}$, we separate the normal modes into two types under the harmonic approximation: even modes, where $g_{z}\left(Q_{\text {even }}\right)=$ $g_{z}\left(-Q_{\text {even }}\right)$ and odd modes, where $g_{z}\left(Q_{\text {odd }}\right)=-g_{z}\left(Q_{\text {odd }}\right)$. For the former, at the equilibrium geometry, $\frac{\partial g_{z}}{\partial Q_{\text {even }}}=0$ and $\frac{\partial^{2} g_{z}}{\partial Q_{\text {even }}^{2}} \neq 0$. For the latter, $\frac{\partial g_{z}}{\partial Q_{\text {odd }}} \neq 0$ and $\frac{\partial^{2} g_{z}}{\partial Q_{o d d}^{2}}=0$.

Under the harmonic approximation, the first term in the expansion (equation 5) is non-zero for odd modes, while the second term is non-zero for even modes. It is clear from this expression that odd modes have a larger impact on the variance of $g_{z}$ and consequently the coherence lifetime. $\partial g_{z} / \partial Q_{i}$ and $\partial^{2} g_{z} / \partial Q_{i}^{2}$ at the equilibrium geometries can be directly related to ligand field parameters in equations 2 and 3. Taking the partial derivative of equation 2 with respect to a vibration coordinate $Q_{i}$ gives:

$$
\partial g_{z} /_{\partial Q_{i}}=8 \xi \frac{\eta\left({ }^{\partial E_{B_{2 g}} / \partial Q_{i}}\right)-E_{B_{2 g}}\left(\partial \eta / \partial Q_{i}\right)}{\left(E_{B_{2 g}}\right)^{2}}
$$

(equation 6)

where $\eta=\alpha_{1}^{2} \beta_{1}^{2}$ and provides adjustments due to covalency. We make the assumption that $\alpha_{1}^{2}$ and $\beta_{1}^{2}$ change linearly with one another at minimal displacements about the equilibrium position and can therefore be represented by a single "covalency" parameter, $\eta$. In the regime where $\eta\left({ }^{\partial E_{B_{2 g}}} / \partial Q_{i}\right) \gg E_{B_{2 g}}\left(\partial \eta / \partial Q_{i}\right), \partial g_{z} / \partial Q_{i}$ will have an inverse square dependence on $E_{B_{2 g}}$. 
Conversely, when $\eta\left(\begin{array}{c}\partial E_{B_{2 g}} / \partial Q_{i} \\ \end{array} \ll E_{B_{2 g}}\left(\partial \eta / \partial Q_{i}\right), \partial g_{z} / \partial Q_{i}\right.$ will have an inverse dependence on $E_{B_{2 g}}$ and a linear dependence with covalency, $\eta$. In both cases, the role of the transition energy is clear: The higher the energy separation from the ground state, the lower the $\partial g_{z} / \partial Q_{i}$ term by at least an inverse dependence. However, as shown below, the complexes considered here are largely in the regime corresponding to an inverse square dependence on $E_{B_{2 g}}$.

For even modes under the harmonic approximation and at the equilibrium geometry, $\partial E_{B_{2 g}} / \partial Q_{i}=\partial \eta / \partial Q_{i}=0$. To describe the variance in the energy gap for even modes, a second partial derivative of $g_{z}$ with respect to the vibrational coordinate is needed.

$$
\partial^{2} g_{z} / \partial Q_{i}^{2}=8 \xi \frac{\left(E_{B_{2 g}}\right)\left(-\partial^{2} \eta / \partial Q_{i}^{2}\right)+\eta\left(\partial^{2} E_{B_{2 g}} / \partial Q_{i}^{2}\right)}{\left(E_{B_{2 g}}\right)^{2}}
$$

(equation 7).

The spin-phonon coupling terms $\partial g_{z} / \partial Q_{i}$ and $\partial^{2} g_{z} / \partial Q_{i}^{2}$ for odd and even modes, respectively, are therefore related to spectroscopic observables and quantities that are easily calculable. It should be noted that the treatment above has been generated with respect to $g_{z}$ of $D_{4 h} \mathrm{Cu}(\mathrm{II})$, but can be done analogously for any $S=1 / 2$ system. At the very least, the equations above can be used as screening tools to estimate relative coherence lifetimes of molecular qubits by estimating parameters such as the relevant $d$-d transition energies and covalencies of the ligand-metal bonds, which can be obtained from quantum chemical calculations. The spin-phonon coupling terms in equations 6 and 7 have been computed for a large scope of $S=1 / 2$ transition metal qubits reported in the literature to establish ligand field principles for manipulating coherence lifetimes.

Below, we utilize $D_{4 h}$ and $D_{2 d}\left[\mathrm{CuCl}_{4}\right]^{2-}$ as structural models to quantitatively evaluate this LFT model using DFT and TDDFT calculations and to define the nature of spin-phonon coupling terms in $\mathrm{Cu}(\mathrm{II})$ complexes. This analysis is then translated to $C_{4 v}\left[\mathrm{VOCl}_{4}\right]^{2-}$ and finally to a variety of $\mathrm{Cu}(\mathrm{II})$ - and $\mathrm{V}(\mathrm{IV})$-based molecular qubits reported in the literature. 


\subsection{Spin-Phonon Coupling Terms in $\left[\mathrm{CuCl}_{4}\right]^{2-}$.}

\subsection{1. $D_{4 h}\left[\mathrm{CuCl}_{4}\right]^{2-}$.}

Depending on the counterion, $\left[\mathrm{CuCl}_{4}\right]^{2-}$ can exist in a series of distorted $T_{d}$ geometries along the $D_{4 h}$ to $D_{2 d}$ coordinate. This distortion coordinate is governed by the $\mathrm{Cl}-\mathrm{Cu}-\mathrm{Cl}$ angle, $\alpha$. A broad range of spectroscopic methods have defined the electronic structures of $D_{4 h}$ and $D_{2 d}\left[\mathrm{CuCl}_{4}\right]^{2-}$. By correlating calculations to these data, Solomon et al. ${ }^{57,58}$ have developed a spectroscopically calibrated DFT-based methodology that accurately reproduces the experimental data and thus the bonding (e.g., covalency). Key to this description is the incorporation of 38\% Hartree-Fock (HF) exchange into the DFT exchange correlation functional. ${ }^{57,58}$ This methodology has been used for calculations presented in this section. As discussed in the Methods (see Supporting Information), a calibrated amount of HF exchange is determined independently for each case considered in subsequent sections.

The DFT calculated g-values and excited state energies for an idealized $D_{4 h}\left[\mathrm{CuCl}_{4}\right]^{2-}$ structure are compared to experiment in Tables 1 and 2, respectively. Note for both $D_{2 d}$ and $D_{4 h}$ $\left[\mathrm{CuCl}_{4}\right]^{2-}$, idealized structures give nearly identical results to those resulting from crystal structures $^{61}$; for a more direct comparison to group theory, only results from the idealized structures are presented here (see Methods in Supporting Information and Table S1a/b for bond distances and angles). Experimentally, the $D_{4 h} \mathrm{~g}_{z^{-}}$and $\mathrm{g}_{\mathrm{x}, \mathrm{y}}$-values are 2.221 and 2.040, respectively. ${ }^{62,63}$ The calculated values for an idealized geometry based on the X-ray crystallographic structure are 2.204 and 2.056, respectively, in agreement with experiment. The $\mathrm{HF}$ dependence of the $\mathrm{g}_{\mathrm{z}}$-value for this structure is given in Figure $\mathrm{S} 1$.

A vibrational frequency analysis was carried out using the idealized $D_{4 h}\left[\mathrm{CuCl}_{4}\right]^{2-}$ structure. The energies, symmetry labels, and scaled vector displacements for all nine normal modes of vibration are given in Table S2a. Using these vibrations, full spin-phonon analyses using the calculated g-values were carried out as described in the Methods section. The coupling terms for $g_{z}\left(g_{\|}\right)$are first described, followed by analyses of $g_{x, y}\left(g_{\perp}\right)$. Briefly, the coupling term for a given g-value and vibrational mode is determined by calculating the g-value along positive and negative distortions about a given normal mode, and the magnitude of the coupling term can be qualitatively estimated by the magnitude of the slope (for odd modes) or curvature (for even modes). The spinphonon coupling term calculations for the $\mathrm{g}_{\mathrm{z}}$-value of idealized $D_{4 h}\left[\mathrm{CuCl}_{4}\right]^{2-}$ are given in Figure 2A, and their fits are given in Table S3a. Note these fits are reported for the scaled vibrational 
displacements and are converted for comparison purposes when possible to $\AA^{-1}$ or ${ }^{0-1}$. The largest coupling term is observed for the totally symmetric $a_{l g}$ breathing mode (mode 7, $296 \mathrm{~cm}^{-1}$ ), which shows a strong linear dependence between the $\mathrm{g}_{\mathrm{z}}$-value and the vibrational coordinate. Note the calculated frequency for the $a_{l g}$ mode is in fairly good agreement with experimental vibrational energy $\left(276 \mathrm{~cm}^{-1}\right) .{ }^{58}$ For the $a_{l g}$ mode, a linear fit along the vibrational mode, $Q_{i}$, provides a slope of $-0.241 \mathrm{~g}_{z} / Q_{i}\left(0.482 \mathrm{~g}_{z} / \AA\right)$. Interestingly, the spin-phonon coupling terms for the totally symmetric stretch exhibit insightful trends when compared to $D_{2 d}\left[\mathrm{CuCl}_{4}\right]^{2-}$ and $C_{4 v}\left[\mathrm{VOCl}_{4}\right]^{2-}$, while also correlating with experimental coherence properties as discussed below.

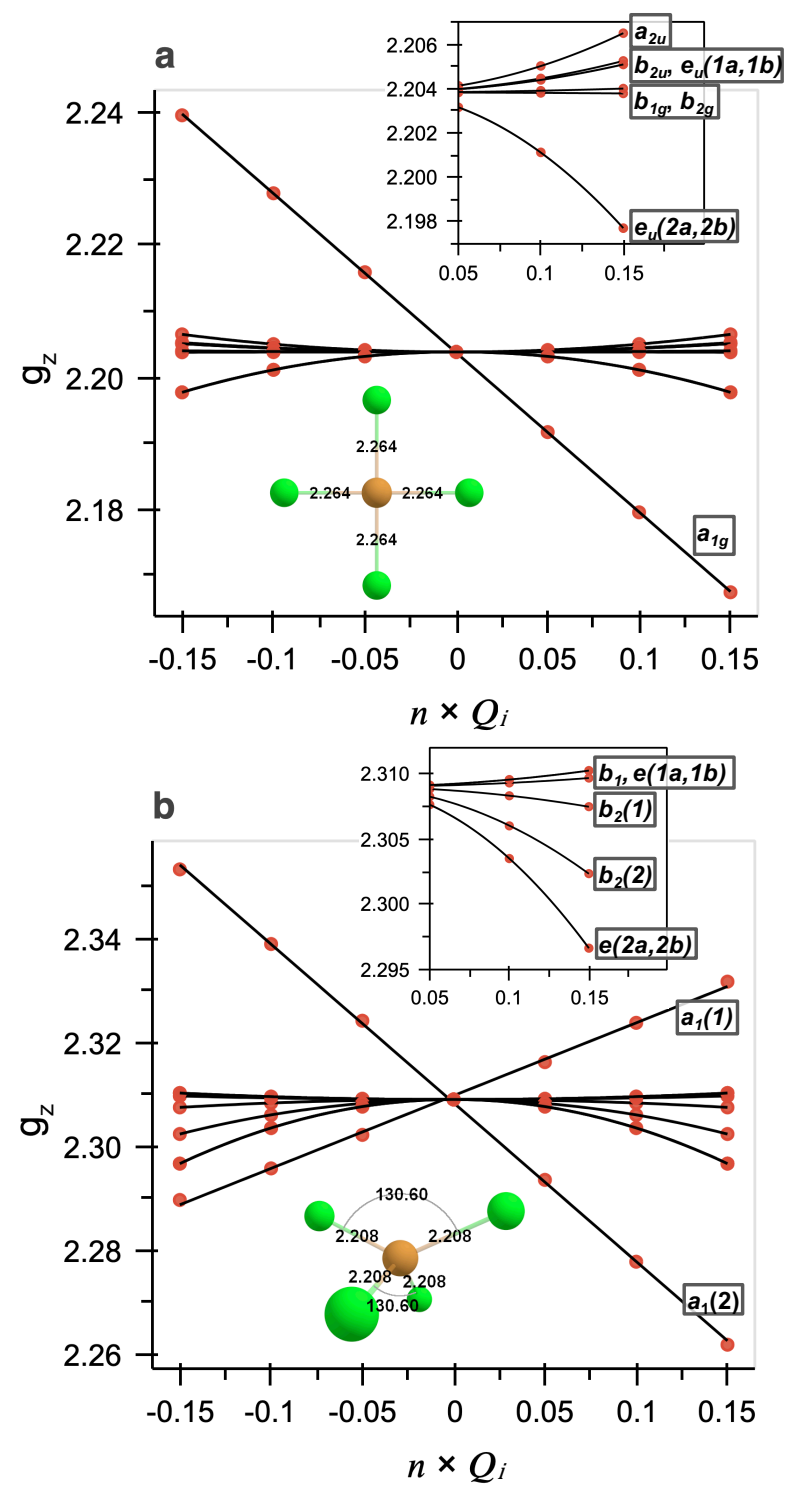

Figure 2. Evolution of the $\mathrm{g}_{\mathrm{z}}$-values along each normal mode of vibration for idealized structures of (a) $D_{4 h}$ and (b) $D_{2 d}\left[\mathrm{CuCl}_{4}\right]^{2-}$. Insets provide zoomed in views for positive distortion and pictorial representations of the respective molecules. 
Of the other vibrational modes, $1\left(b_{2 u},-86 \mathrm{~cm}^{-1}\right), 2\left(a_{2 u}, 140 \mathrm{~cm}^{-1}\right), 3 / 4\left(e_{u}(1 a, 1 b), 172\right.$ $\left.\mathrm{cm}^{-1}\right)$, and 8/9 $\left(e_{u}(2 a, 2 b), 342 \mathrm{~cm}^{-1}\right)$ are even modes with quadratic coupling terms. The $a_{2 u}$ and $e_{u}(2 a, 2 b)$ modes exhibit the largest coupling terms (0.119 and $-0.272 \mathrm{~g}_{\mathrm{z}} / Q_{i}$, respectively) and involve motion of the metal out-of-plane and in-plane, respectively (Table S2a). For the $a_{2 u}$ mode, the slope can be better quantified by using the amount of metal displacement and gives $0.216 \mathrm{~g}_{\mathrm{z}} / \AA$. The coefficients for the $b_{2 u}$ and $e_{u}(1 a, 1 b)$ modes are -0.063 and $-0.056 \mathrm{~g}_{\mathrm{z}} / Q_{i}$, respectively. While the quadratic spin-phonon coupling terms of the $e_{u}(2 a, 2 b)$ modes are the largest, they also have the highest calculated frequencies $\left(342 \mathrm{~cm}^{-1}\right)$ and are therefore not considered in detail here, as these modes will not be as thermally populated past their zero-point energies at practical temperatures. Finally, modes $5\left(b_{2 g}, 183 \mathrm{~cm}^{-1}\right)$ and $6\left(b_{1 g}, 198 \mathrm{~cm}^{-1}\right)$ exhibit negligible spin-phonon coupling terms with the $\mathrm{g}_{\mathrm{z}}$-value (Table S3a). Note, however, the corresponding coupling terms are substantially smaller when the magnetic field is oriented along $\boldsymbol{L}_{x}$ or $\boldsymbol{L}_{y}$ (i.e., for $\mathrm{g}_{\mathrm{x}, \mathrm{y}}$-values). Also, the spin-phonon coupling term for the $b_{2 u}$ mode is increased substantially in the $D_{2 d}$ structure. These observations are discussed further below.

Table 1. Comparisons between a variety of experimental and calculated g-values for $D_{4 h}$ and $D_{2 d}$ $\left[\mathrm{CuCl}_{4}\right]^{2-}$ and other $\mathrm{Cu}(\mathrm{II})$ complexes.

\begin{tabular}{|c|c|c|c|c|c|c|}
\hline \multirow[t]{2}{*}{ Molecule } & \multicolumn{2}{|c|}{$\mathrm{g}_{\mathrm{z}}$} & \multicolumn{2}{|c|}{$\mathrm{g}_{\mathrm{y}}$} & \multicolumn{2}{|c|}{$g_{x}$} \\
\hline & Exp. & Calc. & Exp. & Calc. & Exp. & Calc. \\
\hline$D_{4 h}\left[\mathrm{CuCl}_{4}\right]^{2-\mathrm{a}}$ & 2.221 & 2.204 & 2.040 & 2.057 & 2.040 & 2.054 \\
\hline$D_{4 h}\left[\mathrm{CuCl}_{4}\right]^{2-\mathrm{b}}$ & 2.221 & 2.204 & 2.040 & 2.056 & 2.040 & 2.056 \\
\hline$D_{2 d}\left[\mathrm{CuCl}_{4}\right]^{2-\mathrm{a}, \mathrm{c}}$ & 2.435 & 2.304 & 2.079 & 2.123 & 2.079 & 2.065 \\
\hline$D_{2 d}\left[\mathrm{CuCl}_{4}\right]^{2-\mathrm{b}}$ & 2.435 & 2.309 & 2.079 & 2.095 & 2.079 & 2.095 \\
\hline$\left[\mathrm{Cu}(\mathrm{mnt})_{2}\right]^{2-\mathrm{d}}$ & 2.091 & 2.085 & - & 2.039 & - & 2.036 \\
\hline $\mathrm{CuPc}^{\mathrm{e}}$ & 2.199 & 2.163 & 2.052 & 2.026 & 2.052 & 2.026 \\
\hline $\mathrm{CuN}_{4}(\mathrm{H})^{\mathrm{f}}$ & 2.19 & 2.196 & - & 2.055 & - & 2.063 \\
\hline $\mathrm{CuN}_{4}(\mathrm{Me})^{\mathrm{f}}$ & 2.205 & 2.218 & - & 2.053 & - & 2.078 \\
\hline $\mathrm{CuN}_{4}(\mathrm{t}-\mathrm{Bu})^{\mathrm{f}}$ & 2.28 & 2.273 & - & 2.049 & - & 2.141 \\
\hline$\left[\mathrm{Cu}(\mathrm{bdt})_{2}\right]^{2-\mathrm{g}}$ & 2.085 & 2.047 & 2.019 & 2.015 & 2.019 & 2.016 \\
\hline$\left[\mathrm{Cu}(\mathrm{bds})_{2}\right]^{2-\mathrm{h}}$ & 2.082 & 2.089 & 2.018 & 2.053 & 2.018 & 2.031 \\
\hline
\end{tabular}

${ }^{a}$ Crystal structure from ref. 61, g-values from ref. 62 .

${ }^{\mathrm{b}}$ Idealized structure from crystal structure.

${ }^{\mathrm{c}}$ g-values from ref. 63.

${ }^{\mathrm{d}}$ Crystal structure and g-values from ref. 14.

${ }^{\mathrm{e}}$ DFT optimized structure, g-values from ref. 72.

${ }^{\mathrm{f}}$ DFT optimized structure, experimental g-values from ref. 69.

g Crystal structure from ref. 73, g-values from ref. 33 .

${ }^{\mathrm{h}}$ Crystal structure and g-values from ref. 33 . 
Table 2. Comparisons between experimental and calculated ligand field transitions for $D_{4 h}$ and $D_{2 d}\left[\mathrm{CuCl}_{4}\right]^{2-}$.

\begin{tabular}{|l|l|l|l|l|l|l|l|}
\hline $\begin{array}{c}\text { Exp. } \\
\left(\mathbf{c m}^{-1}\right)^{\mathbf{c}}\end{array}$ & Assignment & $\begin{array}{c}\text { Calc. } \\
\left(\mathbf{c m}^{-1}\right)^{\mathrm{a}}\end{array}$ & $\begin{array}{c}\text { Calc. } \\
\left(\mathbf{( m}^{-1}\right)^{\mathrm{b}}\end{array}$ & $\begin{array}{c}\text { Exp. } \\
\left(\mathbf{( c m}^{-1}\right)^{\mathbf{c}}\end{array}$ & Assignment & $\begin{array}{c}\text { Calc. } \\
\left(\mathbf{c m}^{-1}\right)^{\mathbf{a}}\end{array}$ & $\begin{array}{c}\text { Calc. } \\
\left(\mathbf{c m}^{-1}\right)^{\mathrm{b}}\end{array}$ \\
\hline$D_{4 h}$ & & & & $D_{2 d}$ & & & \\
\hline 12000 & ${ }^{2} \mathrm{~B}_{1 \mathrm{~g}} \rightarrow{ }^{2} \mathrm{~B}_{2 \mathrm{~g}}$ & 14470 & 14475 & 5500 & ${ }^{2} \mathrm{~B}_{2} \rightarrow{ }^{2} \mathrm{E}$ & 6470 & 6825 \\
\hline 13500 & ${ }^{2} \mathrm{~B}_{1 \mathrm{~g}} \rightarrow{ }^{2} \mathrm{E}_{\mathrm{g}}$ & 14525 & 14610 & & & 7360 & 6825 \\
\hline & & 14685 & 14610 & 8000 & ${ }^{2} \mathrm{~B}_{2} \rightarrow{ }^{2} \mathrm{~B}_{1}$ & 10465 & 10440 \\
\hline 16500 & ${ }^{2} \mathrm{~B}_{1 \mathrm{~g}} \rightarrow{ }^{2} \mathrm{~A}_{1 \mathrm{~g}}$ & 15485 & 15485 & 9400 & ${ }^{2} \mathrm{~B}_{2} \rightarrow{ }^{2} \mathrm{~A}_{1}$ & 9130 & 9005 \\
\hline
\end{tabular}

${ }^{a} \mathrm{X}$-ray crystal structure from ref. 61.

${ }^{\mathrm{b}}$ Idealized structure from crystal structure.

${ }^{\mathrm{c}}$ Experimental d-d transitions from ref. 64.

Given the ligand field origin of the SOC induced mixing of orbital angular momentum into the ${ }^{2} \mathrm{~B}_{1 \mathrm{~g}}$ ground state (Figure 1), an analysis of the excited state energies was also carried out. Comparisons between experimental and calculated ligand field transitions are given in Table 2. Experimentally, the ${ }^{2} \mathrm{~B}_{2 \mathrm{~g}},{ }^{2} \mathrm{E}_{\mathrm{g}}$, and ${ }^{2} \mathrm{~A}_{1 \mathrm{~g}}$ ligand field transitions of $D_{4 h}\left[\mathrm{CuCl}_{4}\right]^{2-}$ are observed at 12000,13500 , and $16500 \mathrm{~cm}^{-1}$, respectively. ${ }^{64}$ From equation 2 , the ${ }^{2} \mathrm{~B}_{2 \mathrm{~g}}$ excited state can introduce ground state orbital angular momentum through SOC, and the $\mathrm{g}_{\mathrm{z}}$-value is inversely dependent on the ligand field energy. A TDDFT calculation gives an energy of $14470 \mathrm{~cm}^{-1}$, in fairly good agreement.

The vibrational analysis of the ${ }^{2} \mathrm{~B}_{2 \mathrm{~g}}$ ligand field excited state is given in Figure 3a, and their fits are given in Table S3a. Note the calculation of the ligand field energy along a given vibrational mode provides the excited state coupling term, which takes into account the displacement between the ground and excited state potential energy surfaces (Figure 4a). This displacement of the excited surface relative to the ground state results in a distorting force along a normal mode, $Q_{i}$, in the excited state. This distorting force can be estimated by evaluating the effect of electron-nuclear coupling on the total energy of the excited state, EEs: ${ }^{54}$

$$
E_{\text {elec-nuc }}^{e}=\left\langle\psi_{e}^{\text {elec }}\left|\frac{\partial E_{E S}}{\partial Q_{i}}\right| \psi_{e}^{\text {elec }}\right\rangle Q_{i}
$$

(equation 8) 
For non-zero values of this integral, the excited state will distort along $Q_{i}$ by a value $\Delta Q_{i}$; the excited state coupling term is determined by calculating the energy change in the electronic transition to $\psi_{\mathrm{e}}$ with a change along the coordinate $Q_{i}$. This is shown qualitatively for $D_{4 h}$ and $D_{2 d}$ structures in Figure 4a. The partial derivative $\left(\partial \mathrm{E} / \partial Q_{i}\right)$ reflects the relative curvature of the excited state potential energy surface near the ground state equilibrium geometry (i.e., in the vicinity of the Franck-Condon region). The excited state coupling term therefore provides a means to quantify the change in excited state orbital angular momentum that can SOC into the ground state along a given vibrational coordinate.
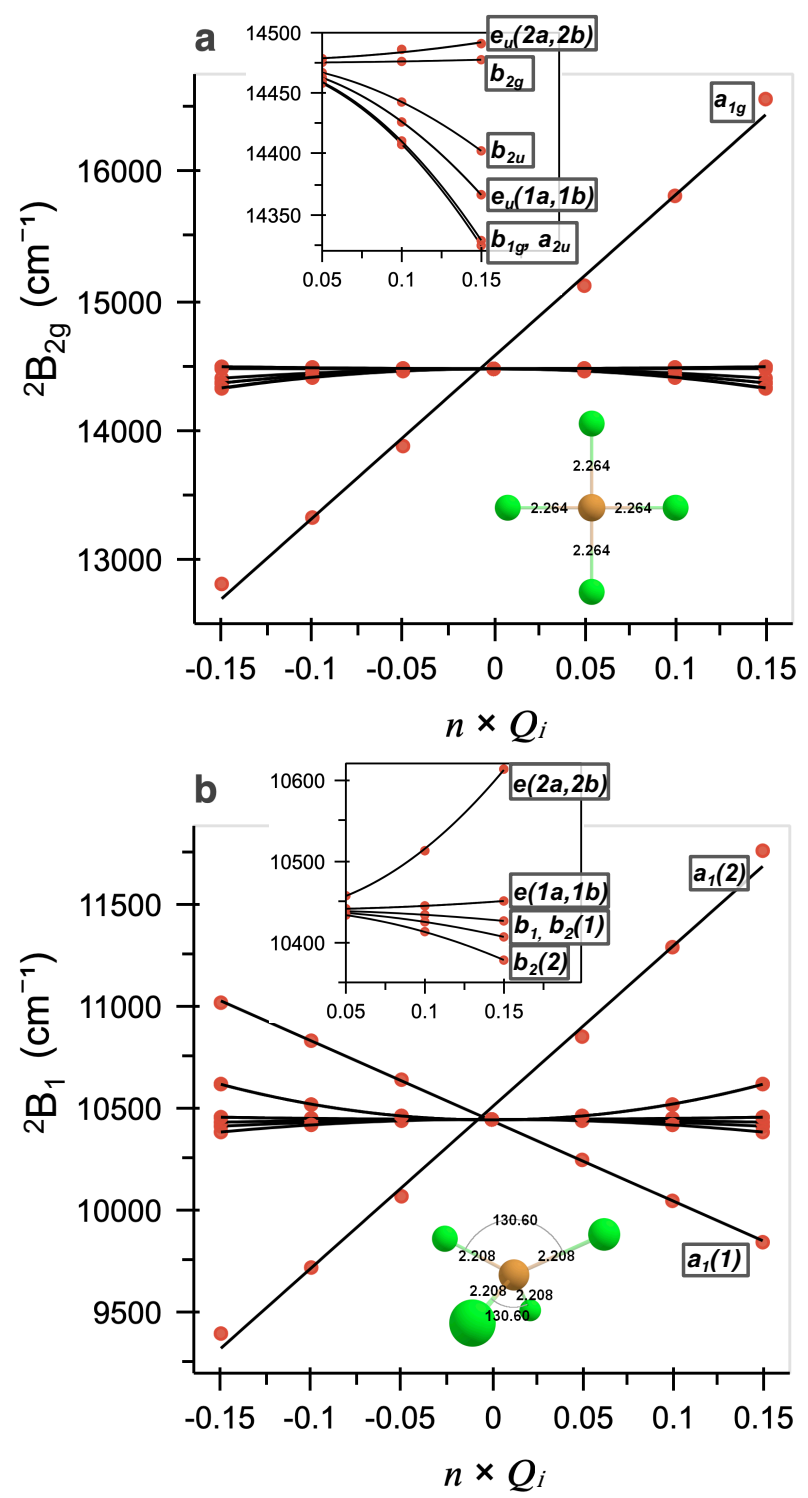

Figure 3. Evolution of the $\mathrm{d}\left(\mathrm{x}^{2}-\mathrm{y}^{2}\right) \rightarrow \mathrm{d}(\mathrm{xy})$ transition energies for (a) $D_{4 h}$ and (b) $D_{2 d}\left[\mathrm{CuCl}_{4}\right]^{2-}$. 


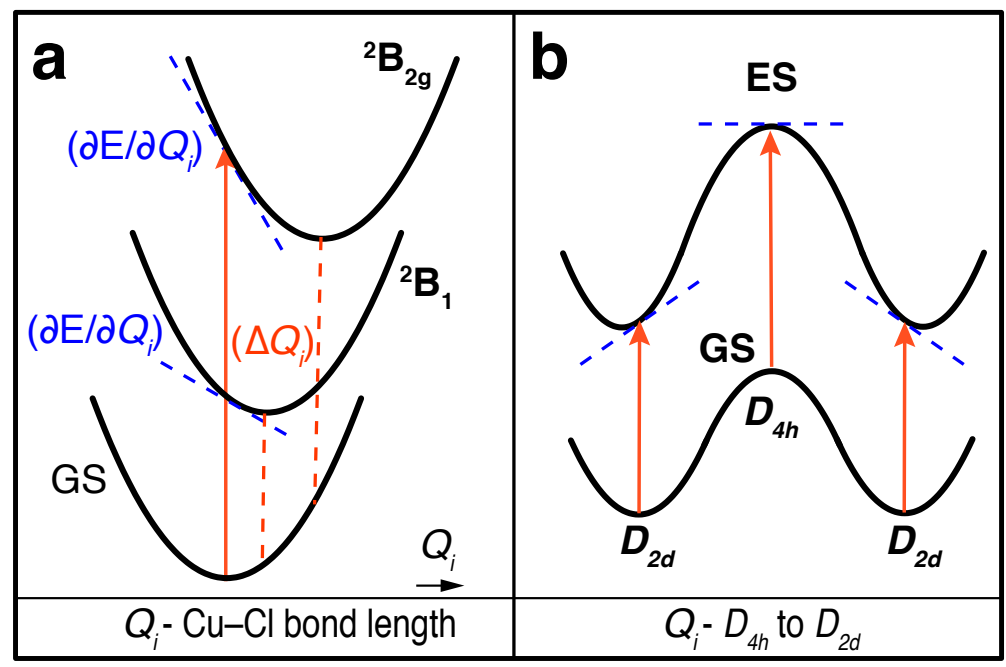

Figure 4. Qualitative potential energy surfaces of $\left[\mathrm{CuCl}_{4}\right]^{2-}$. (a) Excited state linear coupling terms for the totally symmetric $\mathrm{Cu}-\mathrm{Cl}$ stretch, and (b) change in the excited state linear coupling term upon distorting from $D_{4 h}$ to $D_{2 d}$. To simplify (a), the ground state potential energy surfaces of $D_{4 h}$ and $D_{2 d}$ are overlaid even though their $\mathrm{Cu}-\mathrm{Cl}$ bonds do not have the same equilibrium distance.

As with the $\mathrm{g}_{\mathrm{z}}$-value analysis, the totally symmetric $a_{l g}$ mode exhibits the largest coupling term for the ${ }^{2} \mathrm{~B}_{1 \mathrm{~g}}$ excited state (Figure 3a). The slope of the $a_{1 g}$ mode is $12405 \mathrm{~cm}^{-1} / Q_{i}$, which gives $-24940 \mathrm{~cm}^{-1} / \AA$. That is, the energy of the ${ }^{2} \mathrm{~B}_{1 \mathrm{~g}}$ state decreases as the ligand-metal bonds are elongated and vice versa. The quadradic terms for the $a_{2 u}$ mode are $-6700 \mathrm{~cm}^{-1} / Q_{i}$ and $-12230 \mathrm{~cm}^{-}$ $1 / \AA$. Note the slopes and curvatures of the ${ }^{2} B_{2 g}$ energy are inverted relative to those for the $g_{z}$-value slope (Figure 2a). This behavior is consistent with equation 2 and the inverse energy dependence on SOC. The other modes discussed above that exhibit spin-phonon coupling terms with the $\mathrm{g}_{z^{-}}$ value also exhibit inverted behavior. For example, the $a_{2 u}$ and $b_{2 u}$ modes exhibit positive quadratic behaviors in Figure $2 \mathrm{a}$ and negative ones in Figure $3 \mathrm{a}$. Note the $b_{\lg }$ mode does not exhibit a substantial coupling term for the $g_{z}$-value but does with the ${ }^{2} \mathrm{~B}_{2 g}$ energy. This is due to the nature of the $b_{1 g}$ vibrational distortion (see Table S2a), which lowers the symmetry from $D_{4 h}$ to $D_{2 h}$ by making two of the $\mathrm{Cu}(\mathrm{II})-\mathrm{Cl}$ bonds, and thus the $\mathrm{x}$ - and $\mathrm{y}$-axes, inequivalent. This turns on a small mixing between a forbidden (in $D_{4 h}$ ) ${ }^{2} \mathrm{~A}_{2 \mathrm{~g}}$ charge transfer state and the ${ }^{2} \mathrm{~B}_{2 \mathrm{~g}}$ ligand field state. Both of these states transform as ${ }^{2} \mathrm{~B}_{1 \mathrm{~g}}$ upon lowering symmetry to $D_{2 h}$. The energy of the forbidden ${ }^{2} \mathrm{~A}_{2 \mathrm{~g}}$ state exhibits a strong dependence on the $b_{1 g}$ mode distortion. Thus, we ascribe the energy shift of 
the ${ }^{2} \mathrm{~B}_{2 \mathrm{~g}}$ state observed in Figure $3 \mathrm{a}$ to this mixing. Also, other than $e_{u}(2 a, 2 b)$ modes, no other modes exhibit this distortion induced mixing, and they maintain their original ligand field compositions observed for the $D_{4 h}$ structure. Thus, the excited state coupling term (equation 8 ) for the ${ }^{2} \mathrm{~B}_{1 \mathrm{~g}} \rightarrow{ }^{2} \mathrm{~B}_{2 \mathrm{~g}}$ excitation provides a means to evaluate the vibrationally induced change in ground state orbital angular momentum and its effect on the $g_{z}$-value.

In addition to excited state SOC, equation 2 indicates covalency contributions are important determinants of molecular g-values. Experimentally, the $\mathrm{Cu}(\mathrm{d})$ character for $\mathrm{D}_{4 h}\left[\mathrm{CuCl}_{4}\right]^{2-}$ is 0.62 $\pm 0.2 .^{57,58}$ The $\beta$-LUMO of the model considered here is given in Figure 1 and reflects a total $\mathrm{Cu}(\mathrm{d})$ character and spin density of $65 \%$ and 0.668 from Loewdin population analysis and spin density, respectively. Importantly, as shown below, the measure of covalency at the equilibrium geometry, by proxy of the spin density, is a key determinant to understanding its role in spin-phonon coupling terms. Thus, the $38 \% \mathrm{HF}$ method applied to a complex with known $\mathrm{Cu}(\mathrm{d})$ character provides an excellent starting point. Fits for the spin-phonon coupling term analyses using $\mathrm{Cu}$ spin densities are given in Table S3e. The fits for the $a_{1 g}$ mode give values of $-0.157 \mathrm{SD} / Q_{i}$ and $0.221 \mathrm{SD} / \AA$. As observed above for $\mathrm{g}_{\mathrm{z}}$-values and the ${ }^{2} \mathrm{~B}_{2 \mathrm{~g}}$ energies, the largest coupling term for $\mathrm{Cu}$ spin density is observed for the totally symmetric $a_{l g}$ mode. For this mode, the change in covalency along the $a_{\lg }$ coordinate contributes in the same direction/sign to the change in $\mathrm{g}_{\mathrm{z}}$-value as the ${ }^{2} \mathrm{~B}_{2 \mathrm{~g}}$ ligand field energy. This is also the case for the $b_{2 u}$ mode. The concerted contribution from ligand field energies and covalency is not observed for all modes, however. From example, the Cu spin density contribution for the $a_{2 u}$ mode opposes the contribution to the $\mathrm{g}_{\mathrm{z}}$-value from the ${ }^{2} \mathrm{~B}_{1 \mathrm{~g}}$ excited state and illustrates an important interplay between excited state SOC and covalency to the resulting spin-phonon coupling term for the $\mathrm{g}_{\mathrm{z}}$-value.

The individual contributions to the $\mathrm{g}_{\mathrm{z}}$-value from the ${ }^{2} \mathrm{~B}_{1 \mathrm{~g}}$ energy and $\mathrm{Cu}$ spin density can be estimated using equation 2 in combination with the DFT and TDDFT calculations. For example, for $D_{4 h}\left[\mathrm{CuCl}_{4}\right]^{2-}$, using the calculated $\mathrm{Cu}$ spin density of 0.668 and the ${ }^{2} \mathrm{~B}_{1 \mathrm{~g}}$ energy of $14475 \mathrm{~cm}^{-}$ , equation 2 predicts a $g_{z}$-value of 2.205. This is similar to the DFT calculated $g_{z}$-value (2.204). For each mode, the relative change in spin density and/or ${ }^{2} \mathrm{~B}_{1 \mathrm{~g}}$ energy can be used to estimate a change in $g_{z}$-value. The $g_{z}$-value estimated from equation 2 can thus be compared directly to the DFT calculated change in $g_{z}$-value along each vibrational coordinate. These plots for all normal modes and each g-value are given in Figures S3-S5; the results for the $b_{2 u}, a_{2 u}$, and $a_{1 g}$ modes are given in Figures 5 (a-c), respectively. From these comparisons for the $b_{2 u}$ mode (Figure $5 \mathrm{a}$ ), the 
$\mathrm{Cu}$ spin density and ${ }^{2} \mathrm{~B}_{2 \mathrm{~g}}$ energy both contribute appreciably to the change in $\mathrm{g}_{\mathrm{z}}$-value. Furthermore, for the $a_{2 u}$ mode (Figure 5b), the change in $\mathrm{g}_{\mathrm{z}}$-value is largely due to the change in the ${ }^{2} \mathrm{~B}_{2 \mathrm{~g}}$ energy; as mentioned above, a small component from the $\mathrm{Cu}$ spin density component actually opposes the change in $\mathrm{g}_{\mathrm{z}}$-value determined by the ${ }^{2} \mathrm{~B}_{2 \mathrm{~g}}$ energy alone. Lastly, for the $a_{1 g}$ mode, the change in the $\mathrm{g}_{\mathrm{z}}$-value is largely due to the change in ${ }^{2} \mathrm{~B}_{2 \mathrm{~g}}$ energy, but the spin density component contributes to a small extent. Thus, this analysis (Figure 5 and Figures S3-S5) provides a means to qualitatively decompose the spin-phonon coupling term contributions from ground state covalency and orbital angular momentum from excited state SOC.
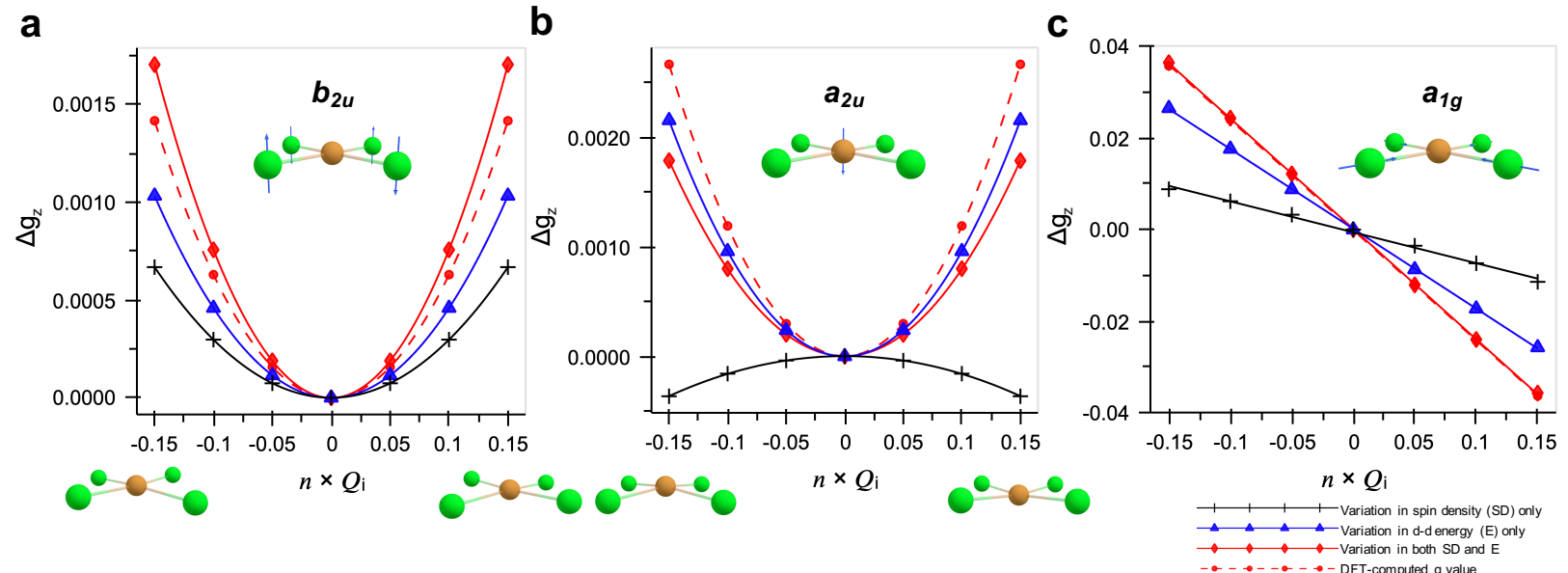

Figure 5. Independent contributions from $d$-d transition energy and ligand-metal covalency to the change in $\mathrm{g}_{z}$ for $D_{4 h}\left[\mathrm{CuCl}_{4}\right]^{2-}$. Comparisons are made between the $\Delta \mathrm{g}_{\mathrm{z}}$ as calculated from the LFT expression and as computed using ORCA for modes (a) $b_{2 u}$, (b) $a_{2 u}$, and (c) $a_{1 g}$. For these plots, the square of the spin density on $\mathrm{Cu}$ was used as a proxy for the covalency. Vector displacements are provided for each vibrational distortion.

The spin-phonon coupling terms for the $\mathrm{g}_{\mathrm{x}, \mathrm{y}}$-values for the $D_{4 h}$ structure are given in Figure S9, with the corresponding fits given in Table S3b and S3c. The coupling terms for the $g_{x^{-}}$and $g_{y^{-}}$ values are very similar except for the inversion of the $e_{u}$ modes (e.g., the $1 a / 2 a$ components switch with the $2 a / 2 b$ components). As with the $\mathrm{g}_{\mathrm{z}}$-value, the largest coupling term for the $\mathrm{g}_{\mathrm{x}, \mathrm{y}}$-values is observed for the $a_{l g}$ mode $\left(-0.072 \mathrm{~g}_{\mathrm{z}} / Q_{i}\right.$,). However, the coupling term for the $\mathrm{g}_{\mathrm{x}, \mathrm{y}}$-values is significantly less than that observed for $\mathrm{g}_{\mathrm{z}}$-values $\left(-0.241 \mathrm{~g}_{\mathrm{z}} / Q_{i}\right)$ by a factor of $\sim 3.3$. This difference reflects the ratio of the prefactors given in equations 2 and 3, as well as contributions from anisotropic covalency. The other modes show a similar behavior between $g_{x}-$ and $g_{z}$-values and therefore are not discussed here. However, while the $b_{1 g}$ mode exhibited a negligible spin-phonon 
coupling term for the $\mathrm{g}_{\mathrm{z}}$-value (Figure 2a), it exhibits a larger coupling term for the $\mathrm{g}_{\mathrm{x}, \mathrm{y}}$-values (Figures S8a/b). Thus, the main differences between the $g_{z}$ and $g_{x, y}$ regions is the magnitude and anisotropy of the spin-phonon coupling terms, with different vibrational modes (e.g., $b_{\lg }$ mode) being selectively activated in the $\mathrm{g}_{\perp}$ region.

The corresponding spin-phonon coupling terms of the two components of the ${ }^{2} \mathrm{E}_{\mathrm{g}}$ excited state are given in Figure S10. The correlation between the $g_{x, y}$-values and the excited state SOC is similar to that laid out for the $g_{z}$-value and is therefore not addressed further here.

In summary for $D_{4 h}\left[\mathrm{CuCl}_{4}\right]^{2-}$, up to the totally symmetric stretch, the vibrational modes that exhibit the largest spin-phonon coupling terms are the $a_{2 u}$ and $a_{1 g}$ modes, with the $b_{2 u}$ and $e_{u}$ $(1 a, 1 b)$ modes having smaller coupling terms. Excited state SOC and covalent contributions are both important quantifiers and determinants of spin-phonon coupling terms, and they can either work cooperatively or oppose one another (Figure 5). Lastly, the spin-phonon coupling terms are anisotropic between the $\mathrm{g}_{\|}$and $\mathrm{g}_{\perp}$ regions, with a general decrease in coupling terms in the $\mathrm{g}_{\perp}$ region and an activation of different vibrational modes. This anisotropy may be an interesting way to experimentally probe and explore spin-phonon coupling terms in transition metal complexes and qubits.

\subsection{2. $D_{2 d}$ and Comparisons to $D_{4 h}\left[\mathrm{CuCl}_{4}\right]^{2-}$.}

Experimentally, going from $D_{4 h}$ to $D_{2 d}\left[\mathrm{CuCl}_{4}\right]^{2-}$, the g-values shift from 2.221 and 2.040 to 2.435 and 2.079, respectively (Table 1). The experimental increase in g-values is reproduced by the DFT calculated g-values (2.309 and 2.095, respectively). In addition, the ligand field strength decreases significantly upon distorting to $D_{2 d}$, which results in a decrease in the ligand field transition energies to 5500,8000 , and $9400 \mathrm{~cm}^{-1}$. The transition at $8000 \mathrm{~cm}^{-1}$ is the ${ }^{2} \mathrm{~B}_{2} \rightarrow{ }^{2} \mathrm{~B}_{1}$ transition, which is predicted at $10440 \mathrm{~cm}^{-1}$ using TDDFT. Note in going from $D_{4 h}$ to $D_{2 d}$ group theory requires the ground state transform as ${ }^{2} \mathrm{~B}_{2}$ (Figure 1). ${ }^{64}$ While this formally leads to a switch of the ground state from $\mathrm{x}^{2}-\mathrm{y}^{2}$ to $\mathrm{xy}$, the overall orientation of the orbital with respect to the ligand-metal bonds does not change upon lowering symmetry from $D_{4 h}$ to $D_{2 d}$, and we therefore retain the $\mathrm{x}^{2}$ $\mathrm{y}^{2}$ labeling as done previously. ${ }^{54}$ Translating to the $D_{2 d}$ structure decreases the overlap between the $\mathrm{Cu} \mathrm{d}\left(\mathrm{x}^{2}-\mathrm{y}^{2}\right)$ orbital and the ligand $\mathrm{p}$ orbitals, which results in a decrease in the covalency of the $\mathrm{Cu}-\mathrm{Cl}$ bonds and thus a larger $\mathrm{Cu}$ spin density. As done above for $D_{4 h}$, using the DFT calculated 
spin density, the ${ }^{2} \mathrm{~B}_{1}$ ligand field energy, and equation 2 predicts a $g_{z}$-value of 2.361 , which is in the range of that predicted from the DFT calculation (2.309).

The spin-phonon analysis for the $\mathrm{g}_{\mathrm{z}}$-value of $D_{2 d}\left[\mathrm{CuCl}_{4}\right]^{2-}$ is given in Figure 2B (fits given in Table S4a). Note that group theory provides a means to directly correlate the vibrational modes between the $D_{4 h}$ and $D_{2 d}$ structures. These correlations are applied here and are reflected in the labels of the $D_{2 d}$ figures and tables throughout. As observed for the $D_{4 h}$ structure, the largest coupling term for the $D_{2 d}$ structure is observed for the totally symmetric breathing mode, $a_{l}(2)$ (mode 7, Table S3) ( $a_{\lg }$ in $\left.D_{4 h}\right)$. For the $a_{1}(2)$ mode, a linear fit along the vibrational mode, $Q_{i}$, provides a slope of $-0.306 \mathrm{~g}_{z} / Q_{i}\left(0.612 \mathrm{~g}_{z} / \AA\right)$. These slopes are larger than those observed for the $a_{l g}$ mode in the $D_{4 h}$ structure $\left(-0.241 \mathrm{~g}_{z} / Q_{i}\right.$ and $\left.0.482 \mathrm{~g}_{\mathrm{z}} / \AA\right)$. Furthermore, while no other modes exhibited substantial linear coupling terms in the $D_{4 h}$ structure, from the spin-phonon analyses in Figure 2B, the $a_{1}(1)$ mode (mode 1 in both $D_{4 h}$ and $D_{2 d} ; b_{2 u}$ in $D_{4 h}$ ) becomes activated and linear in the $D_{2 d}$ structure. For the $a_{1}(1)$ mode, the linear fit along the vibrational mode, $Q_{i}$, provides a slope of $0.140 \mathrm{~g}_{z} / Q_{i}$. The activation of the $a_{1}(1)$ mode and the observation of linear coupling term behavior upon going to the $D_{2 d}$ structure is discussed below.

The quadratic coefficient of the $b_{2}(1)$ mode of the $D_{2 d}$ structure $\left(-0.068 \mathrm{~g}_{z} / Q_{i}\right)$ is reduced relative to the $D_{4 h}$ structure $\left(0.119 \mathrm{~g}_{z} / Q_{i}\right)\left(a_{2 u}\right.$ in $\left.D_{4 h}\right)$. Of the modes with frequencies less than the $a_{1}(2)$ totally symmetric stretch, the $b_{2}(2)$ mode has a quadratic coefficient of $-0.295 \mathrm{~g}_{z} / Q_{i}$, which is activated relative to the $D_{4 h}$ structure in which a very small coupling term was observed ( $b_{l g}$ in $\left.D_{4 h}\right)$.

The spin-phonon analysis for the ${ }^{2} \mathrm{~B}_{1}$ excited state of $D_{2 d}\left[\mathrm{CuCl}_{4}\right]^{2-}$ is given in Figure 3B. Both $a_{l}(2)$ and $a_{l}(1)$ modes exhibit oppositely signed slopes between Figure 2B and 3B, indicating appreciable contributions to the spin-phonon coupling term from excited state SOC. For the $a_{1}(2)$ mode, the linear fit along the vibrational mode, $Q_{i}$, provides a slope of $7885 \mathrm{~cm}^{-1} / Q_{i}\left(-15770 \mathrm{~cm}^{-}\right.$ $1 / \AA)$. Interestingly, these slopes are smaller than those observed for the $a_{\lg }$ mode in the $D_{4 h}$ structure $\left(12405 \mathrm{~cm}^{-1} / Q_{i}\right.$ and $\left.-24940 \mathrm{~cm}^{-1} / \AA\right)$. The larger slope for the $D_{4 h}$ structure might suggest it would have a larger spin-phonon coupling term. However, equation 2 and its differentiated forms predict important behavior in this regard when comparing the $D_{4 h}$ and $D_{2 d}$ structures. This behavior is addressed below.

The slope of the $a_{1}(1)$ mode for the $D_{2 d}$ structure is $-3925 \mathrm{~cm}^{-1} / Q_{i}$, which is roughly half that observed for the $a_{1}(2)$ mode $\left(7885 \mathrm{~cm}^{-1} / Q_{i}\right)$. The activation of this mode is a direct 
consequence of the symmetry about the $\mathrm{Cu}$ complex and its effect on the excited state coupling term (equation 8). This is shown pictorially in Figure $4 \mathrm{~b}$. For the $D_{4 h}$ structure, the $b_{2 u}$ mode is imaginary, representing a saddle point on the ground state potential energy surface. It has also been stressed that the $D_{4 h}\left[\mathrm{CuCl}_{4}\right]^{2-}$ structure arises due to crystal packing forces, and the $D_{2 d}$ structure represents the energetic minimum on the ground state potential energy surface. ${ }^{57}$ However, the symmetry of the complex has important consequence for the excited state coupling term and thus the spin-phonon coupling terms. In the $D_{4 h}$ structure, the excited state that can SOC with the ground state is at an energetic maximum along the $b_{2 u}$ (in $D_{4 h}$ ) mode connecting the $D_{4 h}$ and $D_{2 d}$ structure. Upon distorting along this mode, both the ground and excited state energies are reduced. At the ground state minimum the excited state potential energy surface is shifted relative to the ground state surface. This offset gives rise to a non-zero excited state coupling term for the $D_{2 d}$ structure. As discussed above, a non-zero excited state coupling term provides a mechanism for the amount of orbital angular momentum mixed into the $D_{2 d}$ ground state to change along the vibrational mode. This mixing is prohibited in the $D_{4 h}$ ground state. In some ways, this qualitatively resembles atomic clock transitions that have also been utilized in the development of qubits. ${ }^{35,65-68}$

The spin density as a function of the vibrational coordinate for the $D_{2 d}$ structure is given in Figure S2B. The slopes for the $a_{1}(2)$ mode are $-0.157 \mathrm{SD} / Q_{i}$ and $0.315 \mathrm{SD} / \AA$. These are larger than the values for the $a_{l g}$ mode in the $D_{4 h}$ structure $\left(-0.111 \mathrm{SD} / Q_{i}\right.$ and $\left.0.221 \mathrm{SD} / \AA\right)$. As done for the $D_{4 h}$ structure, the individual contributions to the $\mathrm{g}_{\mathrm{z}}$-value from the ${ }^{2} \mathrm{~B}_{1 \mathrm{~g}}$ energy and $\mathrm{Cu}$ spin density can be estimated using equation 2. These results are given in Figures S6-S8.

The spin-phonon analyses were extended to the $\mathrm{g}_{\mathrm{x}, \mathrm{y}}$-values of $\mathrm{D}_{2 d}\left[\mathrm{CuCl}_{4}\right]^{2-}$. These results are given in Figure S11 and Tables S4b and S4c. The corresponding vibrational analyses are for the ${ }^{2} \mathrm{E}$ excited state of $D_{2 d}\left[\mathrm{CuCl}_{4}\right]^{2-}$ are given in Figure $\mathrm{S} 12$ and Tables S4b and S4b. Similar to $D_{4 h}$, there are new modes that are activated for the $\mathrm{g}_{\mathrm{x}, \mathrm{y}}$-values. For the $D_{2 d}$ structure, these include the $b_{2}(1)$ and $b_{2}(2)$ modes.

In summary, for $D_{2 d}$, in addition to the $a_{1}(2)$ mode, a linear spin-phonon coupling term in the $a_{1}(1)$ mode (i.e., the $b_{2 u}$ parent mode in $D_{4 h}$ ) becomes activated. This is anticipated to be especially important for local mode contributions to decoherence, as the $a_{l}(1)$ mode is the lowest energy mode in these structures and thus can become populated at relatively low temperatures. Indeed, all $\mathrm{Cu}(\mathrm{II})$-based qubits in the literature are roughly square planar, $D_{4 h}$. Insightful and 
quantitative comparisons can be drawn between the vibrational analyses of the total symmetric breathing modes of the $D_{4 h}$ and $D_{2 d}$ structures, with the latter exhibiting a larger spin-phonon coupling term. This larger coupling term occurs even though the excited state coupling term (Figure $4 \mathrm{a}$ ) is larger than the $D_{2 d}$ structure. The activation of the $a_{1}(1)$ mode for the $D_{2 d}$ structure and its excited state coupling behavior can be understood via the qualitative potential energy surfaces in Figure $4 \mathrm{~b}$. Given the ground state structure of $\left[\mathrm{CuCl}_{4}\right]^{2-}$ in the absence of any structural constraints is $D_{2 d}$, going to the $D_{4 h}$ structure on the ground state surfaces results in a scenario where there is a relatively small gradient in the excited state potential energy surfaces. Thus, for the $D_{4 h}$ structure, there is little change in the ground state orbital angular momentum upon fluctuations in the $b_{2 u}$ mode that provides a coordinate between the $D_{4 h}$ and $D_{2 d}$ structures. However, the excited state potential energy surface is offset from the ground state surface near the equilibrium position of the $D_{2 d}$ geometry, which allows for larger changes in ground state orbital angular momentum for the $a_{1}(1)$ mode.

\subsubsection{Cu(II) Effective Decoherence Maps and Comparisons to Ligand Field Theory.}

For $D_{2 d}\left[\mathrm{CuCl}_{4}\right]^{2-}$, the vibrational modes with by far the largest spin-phonon coupling terms were those of $a_{1}(1)$ and $a_{1}(2)$ symmetry, and are consequently expected to be the most impactful to the quantum decoherence of $\mathrm{Cu}(\mathrm{II})$ complexes. The $a_{1}(1)$ mode can be described by the $\mathrm{Cl}-\mathrm{Cu}-\mathrm{Cl}$ bond angle, $\alpha$, while the $a_{1}(2)$ mode can be described by the $\mathrm{Cu}-\mathrm{Cl}$ bond distance. Effective decoherence maps have been generated spanning this space of $\left[\mathrm{CuCl}_{4}\right]^{2-}$ geometries (Figure 6 (ac)). In Figure 6, the magnitude and direction of $\mathrm{g}_{\mathrm{z}}$-value gradients (i.e., effective linear spinphonon coupling terms in this space) are represented by the size and directions of the arrows on the plot. The horizontal and vertical components of the arrows reflect the relative contributions to the $a_{1}(2)$ and $a_{1}(1)$ modes, respectively. It is evident from this representation that, for the $D_{4 h}$ structure, the gradient in $g_{z}$-value is small for any linear combination of these two structural coordinates. However, upon increasing the angle, $\alpha$, the gradient in $\mathrm{g}_{z}$ systematically increases. This reflects the larger slope of the $\mathrm{g}_{\mathrm{z}}$-value vs. $\mathrm{Cu}-\mathrm{Cl}$ bond length observed for $D_{2 d}\left(0.612 \mathrm{~g}_{\mathrm{z}} / \AA\right)$ vs. $D_{4 h}\left(0.482 \mathrm{~g}_{\mathrm{z}} / \AA\right)\left[\mathrm{CuCl}_{4}\right]^{2-}$. This map is expected to translate to any four coordinate $\mathrm{Cu}(\mathrm{II})$ complex. Indeed, previous EPR experiments on a large scope of $\mathrm{Cu}$ (II) complexes have concluded that spin relaxation rates are faster for tetrahedrally-distorted geometries vs. square planar geometries. ${ }^{69}$ This observation is fully supported by extension of the model derived here (see 
Figure S19).The 2D maps are also presented for spin density and the ${ }^{2} \mathrm{~B}_{2 \mathrm{~g}} /{ }^{2} \mathrm{~B}_{1}$ ligand field transition energies, wherein the trends in both cases track with expressions in Section 2.1.

Individual ligand field contributions from the ligand field transition energy and spin density are given in Figures 6B and 6C, respectively. Even though the excited state linear coupling term of the ${ }^{2} \mathrm{~B}_{2 g}$ excited state (in $D_{4 h}$ ) is larger than the ${ }^{2} \mathrm{~B}_{1}$ state (in $D_{2 d}$ ) (also compare blue lines in Figure 4A), the resultant effect on the gradient in $g_{z}$-value is smaller because the initial ${ }^{2} B_{2 g}$ state is higher in energy than the ${ }^{2} \mathrm{~B}_{1}$ state. Furthermore, the effective decoherence map generated using the $\mathrm{Cu}$ spin density (Figure 6C) shows that the gradient of the change in absolute value of the spin density increases with increasing angle, $\alpha$. This behavior is similar to Figure $6 \mathrm{~A}$ for $\mathrm{g}_{\mathrm{z}}$. While it is clear that the $D_{2 d}$ structure has a larger spin-phonon coupling term in the $\mathrm{g}_{\mathrm{z}}$-plot alone, the different behaviors for the individual contributions from ligand field transition energy (Figure 6B) and spin density (Figure 6C) are insightful and in line with the expressions derived in Section 2.1.
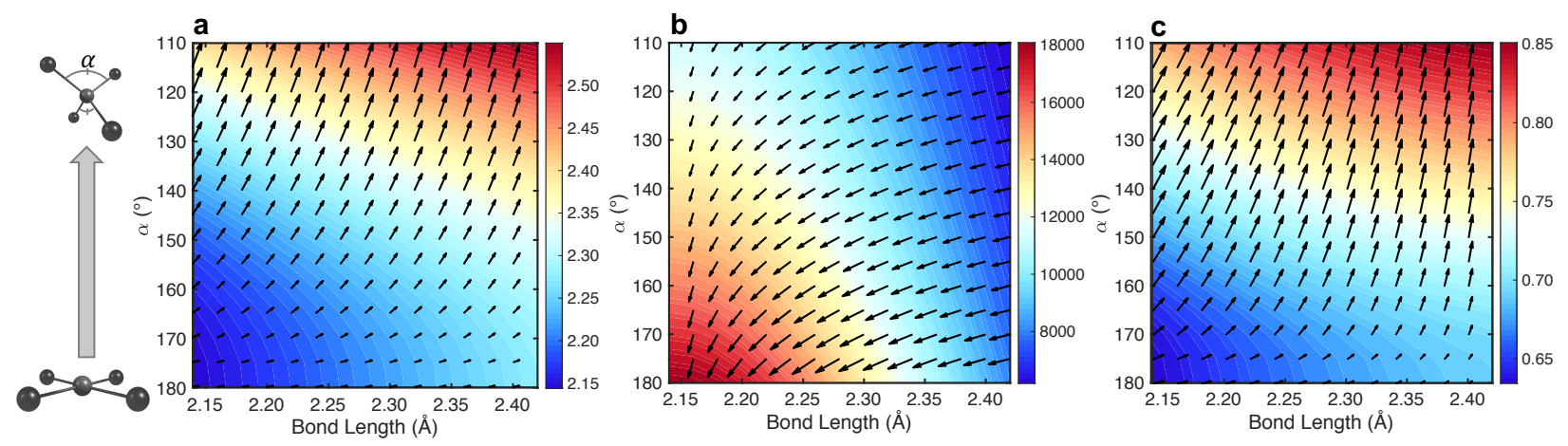

Figure 6. Effective decoherence maps generated using 225 geometries of $\left[\mathrm{CuCl}_{4}\right]^{2-}$ spanning different bond lengths and angles, $\alpha$, and the corresponding gradients (denoted by the size and magnitude of the arrows) in the 2D space. (a) $\mathrm{g}_{\mathrm{z}}$-value, (b) ${ }^{2} \mathrm{~B}_{2 \mathrm{~g}} /{ }^{2} \mathrm{~B}_{1}$ ligand field energy $\left(\mathrm{cm}^{-1}\right)$, and (c) Loewdin spin density on $\mathrm{Cu}$.

\subsection{Spin-Phonon Coupling Terms in $C_{4 v}\left[\mathrm{VOCl}_{4}\right]^{2-}$ and Comparisons to $D_{4 h}\left[\mathrm{CuCl}_{4}\right]^{2-}$.}

The analyses presented above for $\left[\mathrm{CuCl}_{4}\right]^{2-}$ are extended to $\left[\mathrm{VOCl}_{4}\right]^{2-}$. The bond metrics of the $\mathrm{X}-$ ray crystal structure and an idealized $C_{4 v}$ model structure are given in Table S5. As for $\left[\mathrm{CuCl}_{4}\right]^{2-}$, the X-ray structure and idealized structure gave essentially identical results and only the idealized structure is considered. The DFT calculated g-values and ligand field excited state energies for $C_{4 v}$ $\left[\mathrm{VOCl}_{4}\right]^{2-}$ are compared to experiment in Tables 3 and 4, respectively. Experimentally, the $\mathrm{g}_{\mathrm{z}}$ - and $\mathrm{g}_{x, y}$-values of $\left[\mathrm{VOCl}_{4}\right]^{2-}$ are 1.948 and 1.979 , respectively. ${ }^{70}$ The calculated values are 1.963 and 1.973 , respectively, in fair agreement with experiment. The HF dependence of the $g_{z}$-value for this 
structure is given in Figure S13. For overall consistency and accuracy, calculations reported here for $\mathrm{V}(\mathrm{IV})$ complexes utilize $60 \% \mathrm{HF}$ exchange, as this value provides better overall agreement across a variety of other V(IV)-based complexes.

Table 3. Comparisons between a variety of experimental and calculated g-values for $C_{4 v}\left[\mathrm{VOCl}_{4}\right]^{2-}$ and other V(IV) complexes.

\begin{tabular}{|l|c|c|c|c|c|c|}
\hline \multicolumn{1}{|c|}{ Molecule } & \multicolumn{2}{c|}{$\mathrm{g}_{\mathrm{x}}$} & \multicolumn{2}{c|}{$\mathrm{g}_{\mathrm{y}}$} & \multicolumn{2}{c|}{$\mathrm{g}_{\mathrm{z}}$} \\
\hline & Exp. & Calc. & Exp. & Calc. & Exp. & Calc. \\
\hline$C_{4 v}\left[\mathrm{VOCl}_{4}\right]^{2-\mathrm{a}}$ & 1.979 & 1.973 & 1.979 & 1.973 & 1.948 & 1.962 \\
\hline$C_{4 v}\left[\mathrm{VOC}_{4}\right]^{2-\mathrm{b}}$ & 1.979 & 1.973 & 1.979 & 1.973 & 1.948 & 1.963 \\
\hline $\mathrm{VOPc}^{\mathrm{c}}$ & 1.989 & 1.973 & 1.989 & 1.973 & 1.966 & 1.963 \\
\hline $\mathrm{VO}(\mathrm{acac})_{2}{ }^{\mathrm{d}}$ & 1.975 & 1.978 & 1.979 & 1.980 & 1.949 & 1.945 \\
\hline$\left[\mathrm{VO}(\mathrm{cat})_{2}\right]^{2-\mathrm{e}}$ & 1.980 & 1.976 & 1.988 & 1.982 & 1.956 & 1.951 \\
\hline$\left[\mathrm{VO}(\mathrm{dmit})_{2}\right]^{2-\mathrm{f}}$ & 1.986 & 1.979 & 1.988 & 1.977 & 1.970 & 1.963 \\
\hline$\left[\mathrm{V}(\mathrm{bdt})_{3}\right]^{2-\mathrm{g}}$ & 1.970 & 1.947 & 1.970 & 1.949 & 1.988 & 1.962 \\
\hline$\left[\mathrm{V}(\mathrm{bds})_{3}\right]^{2-\mathrm{g}}$ & 1.960 & 1.872 & 1.955 & 1.871 & 1.950 & 1.849 \\
\hline
\end{tabular}

${ }^{a}$ Crystal structure from ref. 76, g-values from ref. 70.

${ }^{\mathrm{b}}$ Idealized structure from crystal structure.

${ }^{\mathrm{c}}$ DFT-Optimized structure. g-values from ref. 75 .

${ }^{\mathrm{d}}$ DFT-Optimized structure. g-values from ref. 77.

${ }^{\mathrm{e}}$ DFT-Optimized structure. g-values from ref. 43.

${ }^{\mathrm{f}} \mathrm{VO}(\mathrm{dmit})_{2}$ : xtal structure and $\mathrm{g}$ values from ref. 53.

${ }^{\mathrm{g}} \mathrm{g}$-values and xtal structures from ref. 33 .

Table 4. Comparisons between experimental and calculated ligand field transitions for $C_{4 v}$ $\left[\mathrm{VOCl}_{4}\right]^{2-}$.

\begin{tabular}{|c|c|c|c|}
\hline $\begin{array}{l}\text { Exp. }^{\mathrm{a}} \\
\left(\mathrm{cm}^{-1}\right)\end{array}$ & Assignment & $\begin{array}{l}\text { Calc. } \\
\left(\mathrm{cm}^{-1}\right)^{\mathrm{b}}\end{array}$ & $\begin{array}{l}\text { Calc. } \\
\left(\mathrm{cm}^{-1}\right)^{\mathrm{c}}\end{array}$ \\
\hline$\sim 12000$ & ${ }^{2} \mathrm{~B}_{2} \rightarrow{ }^{2} \mathrm{~B}_{1}$ & 15080 & 15230 \\
\hline 13700 & ${ }^{2} \mathrm{~B}_{2} \rightarrow{ }^{2} \mathrm{E}$ & 15925 & 16325 \\
\hline & & 16825 & 16325 \\
\hline 22000 & ${ }^{2} \mathrm{~B}_{2} \rightarrow{ }^{2} \mathrm{~A}_{1}$ & 29270 & 19190 \\
\hline
\end{tabular}

${ }^{\mathrm{a}}$ Ref. 71.

${ }^{\mathrm{b}} \mathrm{X}$-ray crystal structure from ref. 76.

${ }^{c}$ Idealized structure from crystal structure.

A vibrational frequency calculation was carried out on the idealized $C_{4 v}\left[\mathrm{VOCl}_{4}\right]^{2-}$ structure. The energies, symmetry labels, and scaled vector displacements for all 12 normal modes of vibration are given in Table S6. Spin-phonon calculations for the $\mathrm{g}_{z}$-value of $C_{4 v}\left[\mathrm{VOCl}_{4}\right]^{2-}$ are given in Figure 7A, and their fits are given in Table S7a. A strong coupling term for the $\mathrm{g}_{\mathrm{z}}$-value 
is observed for the totally symmetric $a_{1}(2) \mathrm{V}(\mathrm{IV})-\mathrm{Cl}$ breathing mode (mode $9,323 \mathrm{~cm}^{-1}$ ). The linear fits provide slopes of $0.068 \mathrm{~g}_{z} / Q_{i}$ and $-0.130 \mathrm{~g}_{z} / \AA$. These slopes are significantly smaller than those observed for $a_{l g} / a_{1}(2)$ modes of either $D_{4 h}\left(-0.241 \mathrm{~g}_{\mathrm{z}} / Q_{i}\right.$ and $\left.0.482 \mathrm{~g}_{\mathrm{z}} / \AA\right)$ or $D_{2 d}(-0.306$ $\mathrm{g}_{z} / Q_{i}$ and $\left.0.612 \mathrm{~g}_{z} / \AA\right)\left[\mathrm{CuCl}_{4}\right]^{2-}$. The ratios of the $C_{4 v}\left[\mathrm{VOCl}_{4}\right]^{2-}$ and $D_{4 h}\left[\mathrm{CuCl}_{4}\right]^{2-}$ slopes are $\sim 0.27$. This is very similar to the relative magnitudes of the V(IV) $\left(250 \mathrm{~cm}^{-1}\right)$ and $\mathrm{Cu}$ (II) $\left(-830 \mathrm{~cm}^{-1}\right) \mathrm{SOC}$ constants ( 0.3$)$. This shows that spin-phonon coupling terms of V(IV) are systematically decreased by a factor of $\sim 3.3$, largely due to the reduced SOC constant of V(IV) relative to $\mathrm{Cu}(\mathrm{II})$.

For $\mathrm{C}_{4 \mathrm{v}}\left[\mathrm{VOCl}_{4}\right]^{2-}$, of the other vibrations with energies less than $a_{1}(2)$, modes $1\left(b_{1}(1),-\right.$ $\left.51 \mathrm{~cm}^{-1}\right), 2 / 3\left(e(1 a, 1 b), 160 \mathrm{~cm}^{-1}\right), 4\left(a_{1}(1), 166 \mathrm{~cm}^{-1}\right), 5\left(b_{2}, 187 \mathrm{~cm}^{-1}\right), 6\left(b_{1}(2), 233 \mathrm{~cm}^{-1}\right), 7 / 8$ $\left(e(2 a, 2 b), 267 \mathrm{~cm}^{-1}\right)$ all exhibit quadratic coupling terms. From low to high energy, the largest quadratic coupling terms are observed for modes $b_{1}(1)\left(-0.016 \mathrm{~g}_{\mathrm{z}} / Q_{i}\right), e(1 a, 1 b)\left(-0.020 \mathrm{~g}_{\mathrm{z}} / Q_{i}\right)$, $a_{1}(1)\left(-0.018 \mathrm{~g}_{\mathrm{z}} / Q_{i}\right), b_{1}(2)\left(-0.016 \mathrm{~g}_{\mathrm{z}} / Q_{i}\right)$, and $e(2 a, 2 b)\left(0.017 \mathrm{~g}_{\mathrm{z}} / Q_{i}\right)$. These quadratic coefficients are significantly less than the important low-energy quadratic modes in $D_{4 h}\left[\mathrm{CuCl}_{4}\right]^{2-}$, which ranged from 0.056 to $0.118 \mathrm{~g}_{\mathrm{z}} / Q_{i}$. When scaled for the different SOC constant of V(IV), the quadratic coefficients for $\left[\mathrm{VOCl}_{4}\right]^{2-}$ range from 0.054 to $0.067 \mathrm{~g}_{2} / Q_{i}$, which are much closer to the those for $D_{4 h}\left[\mathrm{CuCl}_{4}\right]^{2-}$. For more direct comparison, the coefficient of the $b_{2 u}$ mode of $D_{4 h}$ $\left[\mathrm{CuCl}_{4}\right]^{2-}$ is $0.063 \mathrm{~g}_{z} / Q_{i}$, while for the $b_{1}(1)$ mode of $\left[\mathrm{VOCl}_{4}\right]^{2-}$ is $-0.016 \mathrm{~g}_{z} / Q_{i}$. Also, the coefficient of the $a_{2 u}$ mode of $D_{4 h}\left[\mathrm{CuCl}_{4}\right]^{2-}$ is $0.119 \mathrm{~g}_{z} / Q_{i}$, while for the $a_{1}(1)$ mode of $\left[\mathrm{VOCl}_{4}\right]^{2-}$ is -0.018 $\mathrm{g}_{z} / Q_{i}$. From group theory, these modes correlate between the $D_{4 h}$ and $C_{4 v}$ point groups. For example, the $a_{2 u}$ mode involves out-of-plane $\mathrm{Cu}$ motion, while the $a_{1}(1)$ mode involves movement of the vandyl unit out-of-plane with respect to the chloride ligands. Thus, the spin-phonon coupling terms of both linear and quadratic modes are significantly less for the vandyl complex relative to the $\mathrm{Cu}(\mathrm{II})$ complexes. Scaled for angle change, the absolute values of the $b_{2 u}$ and $b_{1}(1)$ slopes are $0.98 \times 10^{-4}\left(\mathrm{~g}_{z}{ }^{\circ}\right)$ and $0.28 \times 10^{-4}\left(\mathrm{~g}_{z}{ }^{\circ}\right)$, respectively, with the $b_{2 u}$ mode being larger by a factor of 3.5. Scaled for metal displacement, the absolute values of the $a_{2 u}$ and $a_{1}(1)$ slopes are 0.216 and $0.077\left(\mathrm{~g}_{z} / \AA\right)$, respectively, with the $a_{2 u}$ mode being larger by a factor of $\sim 2.8$. In both cases, the difference in slope is strongly influenced by the ratio of the SOC constant.

Vibrational analyses of the ${ }^{2} \mathrm{~B}_{1}$ excited state energies were also carried out for $C_{4 v}$ $\left[\mathrm{VOCl}_{4}\right]^{2-}$. Comparisons between experimental and calculated ligand field transitions are given are Table 4. Experimentally, the ${ }^{2} \mathrm{~B}_{1},{ }^{2} \mathrm{E}$, and ${ }^{2} \mathrm{~A}_{1}$ ligand field transitions of $C_{4 v}\left[\mathrm{VOCl}_{4}\right]^{2-}$ are observed at $\sim 12000,13700$, and $22000 \mathrm{~cm}^{-1}$, respectively. ${ }^{71} \mathrm{The}^{2} \mathrm{~B}_{2} \rightarrow{ }^{2} \mathrm{~B}_{1}$ transition provides the SOC of 
orbital angular momentum for $\mathrm{g}_{\mathrm{z}}$, while the ${ }^{2} \mathrm{~B}_{2} \rightarrow{ }^{2} \mathrm{E}$ transition provides SOC for $\mathrm{g}_{\mathrm{x}, \mathrm{y}}$ (Figure 1). A TDDFT calculation gives the energies of these transitions at 15080 and $16325 \mathrm{~cm}^{-1}$, respectively, in fairly good agreement.
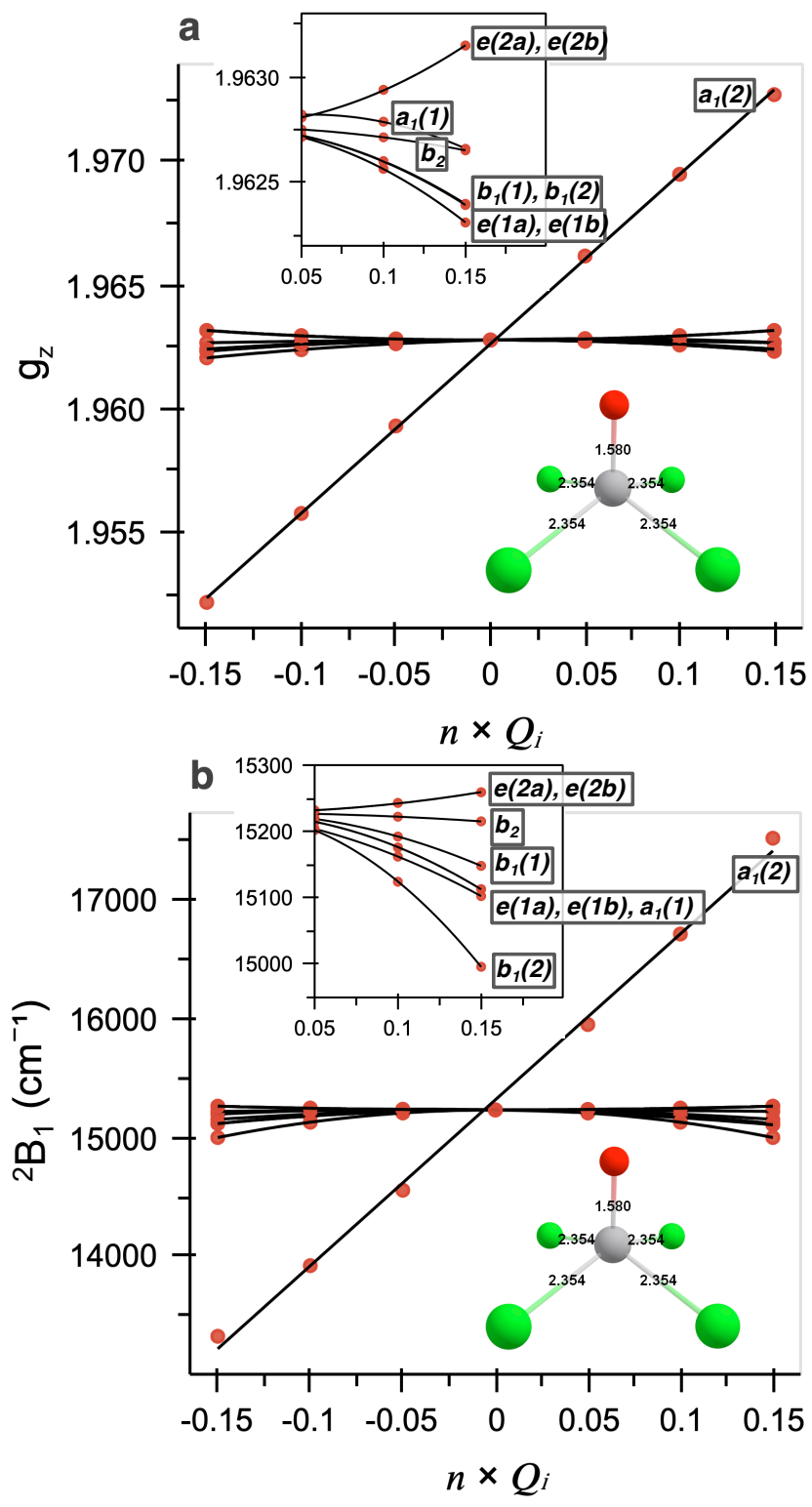

Figure 7. LFT parameters along the vibrational coordinates of the first nine vibrational modes of $\left[\mathrm{VOCl}_{4}\right]^{2-}$. (a) $\mathrm{g}_{\mathrm{z}}$-value, (b) ligand field excited state transition energy.

The vibrational analysis of the ${ }^{2} \mathrm{~B}_{1}$ ligand field excited state is given in Figure $8 \mathrm{~b}$, with fits given in Table S7a. As with the $g_{z}$-value analysis, the totally symmetric $a_{1}(2)$ mode exhibits the 
largest coupling term. The slope of the $a_{1}(2)$ mode is $13945 \mathrm{~cm}^{-1} / Q_{i}\left(-26450 \mathrm{~cm}^{-1} / \AA\right)$. These values are similar to those of $D_{4 h}\left[\mathrm{CuCl}_{4}\right]^{2-}\left(12405 \mathrm{~cm}^{-1} / Q_{i}\right.$ or $\left.-24940 \mathrm{~cm}^{-1} / \AA\right)$. However, despite having similar ligand field excited state energies (14475 vs. $\left.15080 \mathrm{~cm}^{-1}\right)$ and slopes $(-26450$ and -24940 $\mathrm{cm}^{-1} / \AA$ ) for the totally symmetric stretch, the corresponding slopes for the change in $\mathrm{g}_{\mathrm{z}}$-value are significantly lower for $\left[\mathrm{VOCl}_{4}\right]^{2-}$ vs. $\left[\mathrm{CuCl}_{4}\right]^{2-}\left(-0.130 \mathrm{~g}_{z} / \AA\right.$ vs. $0.482 \mathrm{~g}_{z} / \AA$, respectively). This difference is due to the different ratio of SOC constants for $\mathrm{V}(\mathrm{IV})$ and $\mathrm{Cu}(\mathrm{II})$.

The total Loewdin unoccupied V(IV) $\mathrm{d}(\mathrm{xy})$ character and V(IV) spin density for $\left[\mathrm{VOCl}_{4}\right]^{2-}$ are $88 \%$ and 0.98 , respectively. As expected, the covalency of the V(IV)-Cl bonds are significantly lower than those of $D_{4 h}\left[\mathrm{CuCl}_{4}\right]^{2-}$ (e.g., $88 \%$ vs. $65 \%$ unoccupied metal d character). The spin density vibrational analysis for $C_{4 v}\left[\mathrm{VOCl}_{4}\right]^{2-}$ is given in Figure $\mathrm{S} 14$, with fits given in Table S7e. The fits for the $a_{l}(2)$ mode give values of $-0.102 \mathrm{SD} / Q_{i}$ and $0.194 \mathrm{SD} / \AA$. These values are smaller than those observed for $D_{4 h}\left[\mathrm{CuCl}_{4}\right]^{2-}\left(-0.157 \mathrm{SD} / Q_{i}\right.$ and $\left.0.221 \mathrm{SD} / \AA ̊\right)$, consistent with the $\sigma$ overlap in $\left[\mathrm{CuCl}_{4}\right]^{2-}$ (Figure 1). The spin density change for $\left[\mathrm{VOCl}_{4}\right]^{2-}$ is due to the $\pi$-type interaction between the out-of-plane $\mathrm{Cl} p$ orbitals and the $\mathrm{V} \mathrm{d}(\mathrm{xy})$ orbital.

The spin-phonon coupling terms for the $\mathrm{g}_{\mathrm{x}, \mathrm{y}}$-values for the $C_{4 v}$ structure are given in Figure $\mathrm{S} 15$, with the corresponding fits given in Table $\mathrm{S} 7 \mathrm{~b}$ and $\mathrm{S} 7 \mathrm{c}$. Both $\mathrm{g}_{\mathrm{x}}$ and $\mathrm{g}_{\mathrm{y}}$ give similar results, and only $\mathrm{g}_{\mathrm{x}}$ is considered. As observed for $D_{4 h}\left[\mathrm{CuCl}_{4}\right]^{2-}$, the spin-phonon coupling terms are different in the $g_{\perp}$ region relative to $g_{\|}$. For the most part, the magnitudes of the spin-phonon coupling terms are decreased going from $\mathrm{g}_{\|}$to $\mathrm{g}_{\perp}$. For instance, the slope of the $a_{1}(2)$ mode decreases from 0.068 to $0.005 \mathrm{~g}_{z} / Q_{i}$, and the slopes of the $b_{l}(1)$ and $a_{l}(1)$ modes go from -0.016 and $-0.018 \mathrm{~g}_{\mathrm{z}} / Q_{i}$ to -0.002 and $-0.007 \mathrm{~g}_{\mathrm{z}} / Q_{i}$, respectively. The $b_{2}$ and $e(2 a, 2 b)$ modes exhibit an increase in coupling term $\left(0.017\right.$ to $\left.-0.032 \mathrm{~g}_{z} / Q_{i}\right)$. These changes in spin-phonon coupling terms are correlated to the changes in the slopes of the ligand field transitions. The vibrational analyses of the ${ }^{2} \mathrm{E}$ ligand field excited state energies are given in Figure S16. For instance, for the $b_{2}$ mode, the excited state slope changes from -565 to $3775 \mathrm{~cm}^{-1} / Q_{i}$. For the $e(2 a, 2 b)$ modes, the slopes go from 1370 to $-5945 /-9620 \mathrm{~cm}^{-1} / Q_{i}$.

In summary, the totally symmetric $a_{l}(2)$ mode exhibits a strong spin-phonon coupling term for $C_{4 v}\left[\mathrm{VOCl}_{4}\right]^{2-}$. This makes for an insightful comparison to the $a_{l g}$ mode of $D_{4 h}\left[\mathrm{CuCl}_{4}\right]^{2-}$. The magnitude of the spin-phonon coupling term is significantly less for $\left[\mathrm{VOCl}_{4}\right]^{2-}$. This difference in spin-phonon coupling terms could be quantified to a factor of $\sim 0.27$, which is ascribed here to the difference in $\mathrm{SOC}$ constants for $\mathrm{V}(\mathrm{IV})$ vs. $\mathrm{Cu}(\mathrm{II})$. Importantly, $\left[\mathrm{VOCl}_{4}\right]^{2-}$ and $\left[\mathrm{CuCl}_{4}\right]^{2-}$ have 
similar ligand field excited state energies and similar excited state coupling terms, and $\left[\mathrm{VOCl}_{4}\right]^{2-}$ has a smaller slope in covalency, which is due to different relative orbital overlaps for the two complexes. These observations further support that the reduced SOC constant reduces the spinphonon coupling terms. Also, as observed for $\left[\mathrm{CuCl}_{4}\right]^{2-}$, the spin-phonon coupling terms in $\left[\mathrm{VOCl}_{4}\right]^{2-}$ are anisotropic, with different modes being activated in the $\mathrm{g}_{\|}$and $\mathrm{g} \perp$ regions. Nonetheless, the spin-phonon coupling terms of $\left[\mathrm{VOCl}_{4}\right]^{2-}$, even when scaled for degree of distortion, are significantly reduced relative to $\left[\mathrm{CuCl}_{4}\right]^{2-}$ in either $\mathrm{g}_{\|}$and $\mathrm{g}_{\perp}$ directions. The reduced spin-phonon coupling terms will play a major role in the room temperature coherence properties of vanadyl complexes relative to $\mathrm{Cu}(\mathrm{II})$ complexes.

\section{Discussion.}

Transition metal complexes are being explored as qubits for quantum computing. In addition to significant hurdles related to the eventual quantum entanglement of molecular qubits, spin-phonon coupling in transition metal complexes often prohibits the observation of room temperature coherence properties. This has inspired resent research efforts to better understand the nature of spin-phonon coupling in transition metal complexes and how it might be tuned and controlled by variations in the ligand set and thus the ligand field environment. ${ }^{13-15,33,44}$ As highlighted in the Introduction, spin-phonon couplings also play important roles in single molecule magnets and photophysics, and studies directed at fundamental understanding will have broad impact.

Above, we have outlined a general LFT model of spin-phonon coupling terms in $S=1 / 2$ transition metal complexes. This model is derived from the first and second derivatives of the LFT expressions of g-values given in Section 2.1. ${ }^{54}$ While these expressions define the zero temperature magnitudes of spin-phonon coupling terms in $\mathrm{S}=1 / 2$ complexes, they can be expanded to consider additional dynamic effects through the variance of $g_{z},\left\langle g_{z}^{2}\right\rangle$, which highlights the importance of the first derivative, $\frac{\partial g_{z}}{\partial Q_{i}}$, and therefore its role in the coherence lifetimes of $\mathrm{S}=1 / 2$ transition metal complexes. This suggests that, without considering thermal population, odd modes such as totally symmetric stretches will have a more substantial effect on spin-phonon coupling terms and decoherence compared to even modes, in which their value of relevance, $\frac{\partial^{2} g_{z}}{\partial Q_{i}^{2}}$, only appears in the second order term of the Taylor expansion (equation 5). The fundamental behavior of these expressions were borne out by an extensive range of DFT and TD-DFT calculations on 
minimalistic $\mathrm{S}=1 / 2$ models, $D_{4 h} / D_{2 d}\left[\mathrm{CuCl}_{4}\right]^{2-}$ and $C_{4 v}\left[\mathrm{VOCl}_{4}\right]^{2-}$. Together, the results above provide a general description of the roles of transition metal geometric and electronic structure in spin-phonon coupling. For instance, the magnitudes of spin-phonon coupling terms are strongly influenced by excited state SOC of orbital angular momentum into the ground state and are predicted to be strongly influenced by the energy of the particular ligand field excited state mixing with the ground state (equations 6 and 7) (e.g., ${ }^{2} \mathrm{~B}_{2 \mathrm{~g}}$ for a ${ }^{2} \mathrm{~B}_{1 \mathrm{~g}}$ ground state in $D_{4 h}\left[\mathrm{CuCl}_{4}\right]^{2-}$ ). This excited state SOC contribution is governed by the ligand field geometry about the metal complex. For example, going from $D_{4 h}$ to $D_{2 d}\left[\mathrm{CuCl}_{4}\right]^{2-}$ turns on additional mode coupling terms due to the enhancement of excited state coupling terms (Figure 4). Furthermore, the magnitude of spinphonon coupling terms are strongly influenced by the covalency of ligand-metal bonds. This dynamic effect largely reflects a relativistic nephelauxetic effect, which effectively modulates the SOC constant of the metal from that of the free ion. In short, the more covalent the ligand-metal bond, the smaller the spin-phonon coupling terms become. Relatedly, a significant overall reduction in SOC constant can of course be achieved through the use of different transition metal complexes (e.g., V(IV) vs. Cu(II) vs. Cr(V)). As shown below, V(IV), which has a significantly lower SOC constant than $\mathrm{Cu}(\mathrm{II})$, can still maintain favorable spin-phonon coupling terms despite having significantly more ionic ligand-metal bonds than $\mathrm{Cu}(\mathrm{II})$ complexes. Complications can also arise from trying to quantify spin-phonon coupling terms in different ligand field environments, as the nature of the modes can change. However, this can be facilitated to some degree by leveraging specific group theoretical correlations as demonstrated here for $D_{4 h}, D_{2 d}$, and $C_{4 v}$ transition metal complexes. The spin-phonon analyses presented above for $\left[\mathrm{CuCl}_{4}\right]^{2-}$ and $\left[\mathrm{VOCl}_{4}\right]^{2-}$ are now extended to a range of $\mathrm{S}=1 / 2 \mathrm{Cu}(\mathrm{II})$ and $\mathrm{V}(\mathrm{IV})$ molecular qubit candidates.

\subsection{Extension to Cu(II)- and V(IV)-Based Qubits.}

The spin-phonon analyses of the $\mathrm{Cu}(\mathrm{II})$ qubit complexes and their $\mathrm{g}_{\mathrm{z}}$-values are given in Figures S17(a-d) and Tables S8(a-d). The spin-phonon analyses of the V(IV) complexes and their $g_{z}$-values for all modes up to at least $400 \mathrm{~cm}^{-1}$ in energy are given in Figures S18(a-f) and Tables S9(a-f). Comparisons between all geometry optimized and crystal structures are given in Tables S10(a,b) and S11(a-c) for $\mathrm{Cu}(\mathrm{II})$ and V(IV) complexes, respectively. Providing quantitative comparisons between the spin-phonon analyses for different complexes is a complicated task. This is largely because the nature and amount of atomic motions are not necessarily conserved over all vibrations. 
However, as discussed here, the modes identified above for $D_{4 h}\left[\mathrm{CuCl}_{4}\right]^{2-}$ and $C_{4 v}\left[\mathrm{VOCl}_{4}\right]^{2-}$ that exhibited particularly large spin-phonon coupling terms are also those that exhibit spin-phonon coupling terms in the qubits. Thus, the parent vibrational modes provide a means to make quantitative comparisons across $\mathrm{Cu}(\mathrm{II})$ and $\mathrm{V}(\mathrm{IV})$ complexes.

Table 5. Spin-vibrational coupling terms, excited state energies, and covalencies across a variety of $\mathrm{Cu}(\mathrm{II})$ complexes/qubits.

\begin{tabular}{|c|c|c|c|c|c|c|c|}
\hline Complex & $\begin{array}{c}a_{1 g} \\
\left(\mathrm{~cm}^{-1}\right)\end{array}$ & $(g / \AA)$ & $\begin{array}{c}a_{2 u} \\
\left(\mathbf{c m}^{-1}\right)\end{array}$ & $(g / \AA)$ & $\mathbf{E S}^{\mathrm{a}}$ & $\mathbf{M}(\mathbf{d})^{\mathrm{b}}$ & M SD \\
\hline$D_{4 h}\left[\mathrm{CuCl}_{4}\right]^{2-}$ & 296.3 & 0.482 & 140.5 & 0.216 & 14475 & $65 \%$ & 0.670 \\
\hline$D_{2 d}\left[\mathrm{CuCl}_{4}\right]^{2-}$ & 316.7 & 0.612 & 66.9 & 0.529 & 10440 & $70 \%$ & 0.760 \\
\hline $\mathrm{CuPc}$ & 259.4 & 0.464 & 151.7 & 0.151 & 22165 & $72 \%$ & 0.734 \\
\hline $\mathrm{Cu}(\mathrm{mnt})_{2}$ & 303.4 & 0.384 & 141.2 & 0.102 & 22305 & $42 \%$ & 0.434 \\
\hline $\mathrm{Cu}(\mathrm{bdt})_{2}$ & 387.4 & 0.232 & 85.1 & 0.103 & 29700 & $41 \%$ & 0.424 \\
\hline $\mathrm{Cu}(\mathrm{bds})_{2}$ & 199.3 & 0.165 & 97.8 & 0.039 & 24390 & $37 \%$ & 0.377 \\
\hline
\end{tabular}

${ }^{a}$ Excited state which spin orbit couples into the ground state for $\mathrm{g}_{\mathrm{z}}$.

${ }^{\mathrm{b}} \mathrm{M}(\mathrm{d})$ character in unoccupied component orbital from Loewdin population analyses.

${ }^{\mathrm{c}}$ Loewdin metal spin density.

The experimental and calculated g-values of $\mathrm{Cu}$ (II) qubits are given in Table $1,14,33,72,73$ while spin-phonon linear coupling terms and additional computational results are given in Table 5. Note X-ray crystal structures were utilized for $\left[\mathrm{Cu}(\mathrm{mnt})_{2}\right]^{2-},\left[\mathrm{Cu}(\mathrm{bdt})_{2}\right]^{2-}$, and $\left[\mathrm{Cu}(\mathrm{bds})_{2}\right]^{2-}(\mathrm{bds}$ = benzene-1,2-diselenate) complexes, as their structures were not well reproduced using DFT geometry optimization. However, CuPc provided a good agreement and thus the optimized structure is used. As outlined above, the totally symmetric stretch $\left(a_{\lg }\right.$ in $\left.D_{4 h}\left[\mathrm{CuCl}_{4}\right]^{2-}\right)$ and the out-of-plane motion of the metal/vanadyl moiety $\left(a_{2 u}\right.$ in $D_{4 h}\left[\mathrm{CuCl}_{4}\right]^{2-}$ and $a_{1}(1)$ in $C_{4 v}\left[\mathrm{VOCl}_{4}\right]^{2-}$ ) were the main modes to consider. The nature of these modes are well conserved over the complexes considered in Tables 5 and 6 and allow for the spin-phonon coupling terms to be compared on a $\AA^{-1}$ scale. As elucidated above, the linear coupling terms for the totally symmetric modes of $D_{4 h}$ and $D_{2 d}\left[\mathrm{CuCl}_{4}\right]^{2-}$ were determined to be 0.482 and $0.612 \mathrm{~g}_{\mathrm{z}} / \AA$. These modes for qubit candidates $\mathrm{CuPc},{ }^{74} \mathrm{Cu}(\mathrm{mnt})_{2},{ }^{50} \mathrm{Cu}$ (bdt $)_{2},{ }^{33}$ and $\mathrm{Cu}(\mathrm{bds})_{2}{ }^{33}$ are $0.464,0.384,0.232$, and 0.165 $\mathrm{g}_{z} / \AA$, respectively. Interestingly, of these qubits, $\mathrm{Cu}(\mathrm{bdt})_{2}$ exhibited spin echoes that persist to room temperature, and it has one of the lowest spin-phonon coupling terms of the $\mathrm{Cu}(\mathrm{II})$ complexes, with only $\mathrm{Cu}(\mathrm{bds})_{2}$ being lower. Note the lack of spin echoes for $\mathrm{Cu}(\mathrm{bds})_{2}$ and its comparison to $\mathrm{Cu}(\mathrm{bdt})_{2}$ is discussed further below. For the $a_{2 u}$ parent mode, the quadratic 
coefficients for $D_{4 h}$ and $D_{2 d}\left[\mathrm{CuCl}_{4}\right]^{2-}$ were determined to be 0.216 and $0.529 \mathrm{~g}_{\mathrm{z}} / \AA$, respectively. In a similar fashion to the $a_{l g}$ parent mode, the quadratic coefficients of the $a_{2 u}$ parent mode decrease to $0.151,0.102,0.103$, and $0.039 \mathrm{~g}_{\mathrm{z}} / \AA$ for $\mathrm{CuPc}, \mathrm{Cu}(\mathrm{mnt})_{2}, \mathrm{Cu}(\mathrm{bdt})_{2}$, and $\mathrm{Cu}(\mathrm{bds})_{2}$, respectively. Thus, there is a systematic decrease in the spin-phonon coupling terms across these $\mathrm{Cu}(\mathrm{II})$ complexes. These observations can be understood utilizing the LFT model outlined above. For example, $\mathrm{Cu}(\mathrm{bdt})_{2}$ exhibits the highest calculated ligand field excited state energy $\left(29700 \mathrm{~cm}^{-}\right.$ $\left.{ }^{1}\right)$ and has highly covalent ligand-metal bonds $(41 \% \mathrm{Cu}(\mathrm{d}))$. The decreased slope of $\mathrm{Cu}(\mathrm{bds})_{2}$ is due to the increased covalency of the $\mathrm{Cu}-\mathrm{Se}$ vs. $\mathrm{Cu}-\mathrm{S}$ bonds (Table 5). Furthermore, the slopes and quadratic coefficients of $\mathrm{Cu}(\mathrm{mnt})_{2}$ are larger than those $\mathrm{Cu}(\mathrm{bdt})_{2}$ and $\mathrm{Cu}(\mathrm{bds})_{2}$. From Table 5, this is largely reflected by the lower excited state energy $\left(22305 \mathrm{~cm}^{-1}\right.$ ) (and thus the higher amount of ground state orbital angular momentum) and, to a smaller extent, the lower covalency (42\% $\mathrm{Cu}(\mathrm{d})$ ). The slopes and coefficients for $\mathrm{CuPc}$ are increased further relative to the other $\mathrm{Cu}(\mathrm{II})$ complexes, as the $\mathrm{Cu}-\mathrm{N}$ bonds are significantly more ionic than the $\mathrm{Cu}-\mathrm{S}$ bonds of $\mathrm{Cu}(\mathrm{mnt})_{2}$, $\mathrm{Cu}(\mathrm{bdt})_{2}$ and $\mathrm{Cu}(\mathrm{bds})_{2}$.

These electronic differences between $\mathrm{Cu}(\mathrm{bdt})_{2}$ and $\mathrm{Cu}(\mathrm{mnt})_{2}$ can be understood from their $\mathrm{X}$-ray crystal structures. For example, the $\mathrm{Cu}-\mathrm{S}$ bond lengths of $\mathrm{Cu}(\mathrm{mnt})_{2}$ are $\sim 2.33 \AA$, which are longer than those for the $\mathrm{Cu}(\mathrm{bdt})_{2}$ complex $(\sim 2.15 \AA)$. For $\mathrm{Cu}(\mathrm{bdt})_{2}$, the contraction of the ligandmetal bonds destabilizes the $\mathrm{Cud}\left(\mathrm{x}^{2}-\mathrm{y}^{2}\right) \beta$-LUMO orbital, which increases the energy of the ${ }^{2} \mathrm{~B}_{2 \mathrm{~g}}$ ligand field transition and increases the orbital overlap (covalency) of the ligand-metal bonds (Figure 1). Thus, the ligand set and $\mathrm{Cu}(\mathrm{bdt})_{2}$ complex exhibits the ideal characteristics for a $\mathrm{Cu}(\mathrm{II})-$ based qubit. Also, while the slopes of the $\mathrm{Cu}(\mathrm{bds})_{2}$ complex would suggest longer coherence times, the lack of spin echoes at higher temperatures can be attributed to the significant decrease in the vibrational frequency of the $a_{l g}$ parent mode due to the mass effect of the $\mathrm{S}$ to Se conversion (e.g., 387 vs. $199 \mathrm{~cm}^{-1}$, respectively). Interestingly, the fits to the temperature dependence of the $T_{1}$ for these complexes suggest local mode contributions of $488 \pm 72$ and $344 \pm 80 \mathrm{~cm}^{-1}$. Combined with the computational results here, these frequencies and their differences provide strong evidence that the totally symmetric $a_{l g}$ parent mode contributes to the coherence times of $\mathrm{Cu}(\mathrm{II})$ complexes. Thus, we propose that the rapidly accessible data in Table 5 can be computed to qualitatively and semi-quantitatively evaluate and screen potential $\mathrm{Cu}(\mathrm{II})$-based qubits.

Recent work by Sessoli et al. ${ }^{13,53}$ has highlighted the important role of the vanadyl moiety in V(IV)-based qubits. The calculated and experimental g-values of a variety of vandyl and V(IV) 
qubits are given in Table 3. ${ }^{43,53,70,75-77}$ Their spin-phonon analyses are given in Figures S18(a-f) and Tables S9(a-f), and specific spin-phonon slopes and additional computational results are given in Table 6. Note, of the vandyl complexes considered here, VOPc, VO(acac) $)_{2}$, and [VO(cat) $\left.{ }_{2}\right]^{2-}$ were geometry optimized. Similarly to the $\mathrm{Cu}$ complexes considered above, X-ray crystal structures were used for structures where geometry optimizations resulted in significantly different structures (e.g., $\left[\mathrm{VO}(\mathrm{dmit})_{2}\right]^{2-},\left[\mathrm{V}(\mathrm{bdt})_{3}\right]^{2-}$, and $\left.\left[\mathrm{V}(\mathrm{bds})_{3}\right]^{2-}\right)$. Experimentally, long coherence times have been observed for a variety of vandyl complexes. However, only VOPc has been directly studied in a solid diamagnetic matrix, which has thus far prohibited further investigation of vanadyl complexes up to room temperature. From the data given in Table 6, there are currently no clear defining characteristics to be observed across the vanadyl complexes. Thus, other vandyl complexes, when isolated in similar solid diamagnetic matrices, will likely exhibit long relaxation times, with the potential for room temperature coherence.

The spin-phonon model presents a stark difference for vanadyl vs. six coordinate V(IV) complexes. As shown in Sessoli et al., ${ }^{13,53}$ six coordinate V(IV) complexes do not exhibit long $T_{I} \mathrm{~S}$ at elevated temperatures. Very recently, Albino et al. ${ }^{13}$ pointed to the role of increased excited state SOC in six coordinate complexes relative to vanadyl complexes. Furthermore, Fataftah et al. ${ }^{33}$ compared six coordinate $\mathrm{V}$ (IV) complexes to $\mathrm{Cu}$ (II) complexes to suggest the role of increased covalency in elongating $T_{l}$ relaxation lifetimes. Here we have extended our LFT model to the $\mathrm{V}(\mathrm{bdt})_{3}$ and $\mathrm{V}(\mathrm{bds})_{3}$ complexes studied by Fataftah et al. ${ }^{33}$ (Table 6). Interestingly, as pointed out by Albino et al. ${ }^{13}$ for other six coordinate $\mathrm{V}(\mathrm{IV})$ complexes, the $\mathrm{V}(\mathrm{bdt})_{3}$ and $\mathrm{V}(\mathrm{bds})_{3}$ complexes exhibit very low energy calculated ligand field transitions (7935 and $6785 \mathrm{~cm}^{-1}$, respectively). Furthermore, the totally symmetric stretches of these complexes were computed at 351.7 and 209.8 $\mathrm{cm}^{-1}$, respectively. These modes allow for a quantitative comparison between the linear spinphonon coupling term of $\mathrm{Cu}(\mathrm{II})$ complexes on a $\AA^{-1}$ scale. The linear coupling terms for $\mathrm{V}(\mathrm{bds})_{6}$ in the $\mathrm{g}_{\|}$and $\mathrm{g}_{\perp}$ regions are -0.420 and $-0.357 \mathrm{~g} / \AA$, respectively. For comparison, the linear coupling term of the totally symmetric $a_{l g}$ parent mode of $\mathrm{Cu}(\mathrm{bdt})_{2}$ is smaller $\left(0.232 \mathrm{~g}_{\mathrm{z}} / \AA\right)$. Also, the calculated vibrational frequency decreases and the linear coupling terms increase going from $\mathrm{V}(\mathrm{bdt})_{3}$ to $\mathrm{V}(\mathrm{bds})_{3}$. Thus, the longer spin-lattice relaxation time at higher temperatures for $\mathrm{Cu}(\mathrm{bdt})_{2}$ vs. $\mathrm{V}(\mathrm{bdt})_{3}$ is not due to differences in ligand-metal covalency, but rather stems from efficient excited state SOC as a result of the relatively low energy ligand field transition energies for $\mathrm{V}(\mathrm{bdt})_{3}$. This is further supported by the observation of room temperature coherence in vanadyl 
complexes, ${ }^{37}$ despite ionic ligand metal bonding. Together, these DFT/TDDFT calculations are consistent with the LFT model derived here and further highlight the importance of considering both excited state SOC and ligand-metal covalency when comparing different complexes with different metals and/or coordination environments.

Table 6. Spin-vibrational coupling terms across a variety of V(IV) complexes.

\begin{tabular}{|c|c|c|c|c|c|}
\hline Complex & $\begin{array}{l}\text { Mode } \\
\left(\mathbf{c m}^{-1}\right)\end{array}$ & $\left(\mathrm{g}_{z} / Q_{i}\right)$ & $\mathbf{E S}^{\mathrm{a}}$ & $\mathbf{M}(\mathbf{d})^{\mathbf{b}}$ & M SD \\
\hline \multirow[t]{4}{*}{$C_{4 v}\left[\mathrm{VOCl}_{4}\right]^{2-}$} & 166.4 & -0.018 & 15230 & $88 \%$ & 0.983 \\
\hline & 323.5 & 0.068 & & & \\
\hline & 394.9 & -0.313 & & & \\
\hline & 394.9 & -0.322 & & & \\
\hline \multirow{6}{*}{ VOPc } & 177.3 & -0.009 & 22745 & $85 \%$ & 0.985 \\
\hline & 260.0 & -0.006 & & & \\
\hline & 317.3 & -0.014 & & & \\
\hline & 384.2 & -0.063 & & & \\
\hline & 384.2 & -0.059 & & & \\
\hline & 393.9 & -0.017 & & & \\
\hline \multirow[t]{6}{*}{$\mathrm{VO}(\mathrm{acac})_{2}$} & 192.3 & 0.006 & 17955 & $84 \%$ & 0.972 \\
\hline & 277.6 & 0.006 & & & \\
\hline & 295.6 & -0.021 & & & \\
\hline & 374.5 & -0.029 & & & \\
\hline & 391.0 & -0.030 & & & \\
\hline & 475.4 & 0.022 & & & \\
\hline \multirow[t]{5}{*}{$\mathrm{VO}(\mathrm{cat})_{2}$} & 186.1 & -0.004 & 19335 & $65 \%$ & 0.987 \\
\hline & 280.9 & -0.017 & & & \\
\hline & 366.3 & -0.012 & & & \\
\hline & 388.4 & -0.039 & & & \\
\hline & 437.4 & -0.066 & & & \\
\hline \multirow[t]{6}{*}{$\mathrm{VO}(\text { dmit })_{2}$} & 116.8 & -0.003 & 20120 & $50 \%$ & 0.999 \\
\hline & 178.6 & -0.016 & & & \\
\hline & 350.7 & -0.053 & & & \\
\hline & 378.5 & 0.031 & & & \\
\hline & 414.0 & -0.022 & & & \\
\hline & 426.6 & -0.058 & & & \\
\hline Complex & $\begin{array}{l}\text { Mode } \\
\left(\mathrm{cm}^{-1}\right)\end{array}$ & $\left(\mathrm{g}_{||} / \AA\right)$ & $\left(g_{\perp} / \AA\right)$ & ES & \\
\hline $\mathrm{V}(\mathrm{bdt})_{3}$ & 351.7 & -0.420 & -0.357 & 7935 & \\
\hline
\end{tabular}




\begin{tabular}{|l|l|l|l|l|l|}
\hline $\mathrm{V}(\mathrm{bds})_{3}$ & 209.8 & -1.744 & -0.766 & 6785 & \\
\hline
\end{tabular}

${ }^{a}$ Excited state which spin orbit coupling into the ground state.

${ }^{\mathrm{b}} \mathrm{M}(\mathrm{d})$ character in unoccupied component orbital from Loewdin population analyses.

${ }^{\mathrm{c}}$ Loewdin metal spin density.

\subsection{Ligand Field Strain in Qubits.}

As previously highlighted for $D_{4 h} / D_{2 d}\left[\mathrm{CuCl}_{4}\right]^{2-}$, the planar $D_{4 h} \mathrm{Cu}(\mathrm{II})$ structure represents a saddle point on the ground state potential energy surface that can only be stabilized in the presence of crystal packing forces. ${ }^{57,58}$ The formation of this structure in $\left[\mathrm{CuCl}_{4}\right]^{2-}$ was likened to the entatic/rack state in bioinorganic chemistry, where the protein architecture (inclusive of first and second sphere contributions, as well as long range H-bonding and electrostatics) can place a metal ion in a strained ligand field. ${ }^{78-81}$ This ligand field strain can generate unique properties. The entatic/rack state and ligand field strain is therefore of relevance to molecular qubits. For example, $\mathrm{Cu}$ (II)-based complexes with the longest coherence times are square planar $\mathrm{Cu}$ (II) sites stabilized in diamagnetic lattices (e.g., $\mathrm{Cu}(\mathrm{mnt}){ }_{2}{ }^{50}$ and $\mathrm{Cu}(\mathrm{bdt})_{2}{ }^{33}$ ). The geometric dependence to $T_{l}$ was also noted in an EPR study of a variety of $\mathrm{Cu}(\mathrm{II})$ complexes. ${ }^{69}$ Here we have shown that the origin of this dependence for the square planar $\mathrm{Cu}(\mathrm{II})$ geometry derives from the significant minimization of excited state coupling terms, which reduces dynamic SOC of orbital angular momentum into the ground state (Figure 4).

In addition to crystal packing forces, variations in the ligand set can effectively control the deviation from planarity in $\mathrm{Cu}$ (II) complexes. This can be observed directly in the dependence of the electronic energy as a function of the $b_{2 u}$ parent mode (in $D_{4 h}$ ) distortion. For instance, as noted above, distortion along this mode will decrease the energy for the square planar $\mathrm{Cu}(\mathrm{II})$ complexes studied here, which results in the $b_{2 u}$ mode being imaginary. However, this is not the case for CuPc. Thus, linking the four N-based ligands into the aromatic planar structure of the Pc ligand provides an entatic state that can oppose distortions along the $b_{2 u}$ parent mode. However, the drawback of the Pc ligand arises also from its N-based coordination, which gives rise to fairly ionic ligandmetal bonds and opposes the effects provided by the rigid and constrained ligand field (i.e., entatic state).

In relation, significant efforts have been guided toward better identifying, understanding, and quantifying entatic states, ${ }^{82-84}$ which have traditionally been used to rationalize electron transfer properties. However, given the general nature of this description, it is being extended to 
other scenarios, including photochemistry and catalysis. ${ }^{85-89}$ Strain effects have also been discussed in the context of both ground and excited states and their contributions to the coherence properties in solid state qubits (e.g, vacancies in diamond). ${ }^{10-12,90}$ Thus, engineering ligand field strain and rigidity into covalent environments will be useful for advancing the geometric and electronic structural contributions to the quantum coherence of transition metal complexes, and the model outlined here can guide these future investigations.

\section{Conclusion.}

The spin-phonon coupling terms of minimalized $D_{4 h} / D_{2 d}\left[\mathrm{CuCl}_{4}\right]^{2-}$ and $C_{4 v}\left[\mathrm{VOCl}_{4}\right]^{2-}$ complexes translate onto $\mathrm{Cu}(\mathrm{II})$ - and $\mathrm{V}(\mathrm{IV})$-based molecular qubits and are dominated by three major factors: 1) the magnitude of the metal-based SOC constant, 2) the initial magnitude and gradient of change in ground state orbital angular momentum, which is governed by the ligand field excited state energies, and 3) dynamic relativistic nephelauxetic contributions, including the initial magnitude and gradient in the covalency of the ligand-metal bonds. Factors 1) and 3) are directly related, as covalency further reduces the SOC constant of a metal in a complex relative to that of the free ion. LFT expressions derived here predict spin-phonon coupling terms in both odd and even modes are important to consider for decoherence times (equation 5). However, odd modes such as the totally symmetric stretch play a key role for decoherence times. We have further shown how the LFT expressions and thus spin-phonon coupling terms (equations 6 and 7) can be directly related to spectroscopic observables and calculable quantities. For $\mathrm{Cu}(\mathrm{II})$, key geometric and symmetry factors, including ligand field strain, significantly lower excited state coupling terms while simultaneously increasing orbital overlap and ligand-metal covalency. Importantly, all factors relating to excited state SOC and covalency need to be evaluated when comparing spin-phonon coupling terms, including local mode contributions to $T_{l}$ and $T_{m}$ relaxation times, of various metal complexes. The model outlined here provides a means to quantify spin-phonon coupling terms for given vibrational modes for any $S=1 / 2$ molecule, providing a powerful means to benchmark current and future qubit candidates. The further discovery of room temperature coherent materials will provide exciting opportunities to develop fundamental structure-function correlations for spinphonon coupling in transition metal complexes.

\section{Acknowledgments.}


We acknowledge Prof. Edward Solomon, Dr. Alec Follmer, Roman Korol, and Nicholas Higdon

for helpful discussions. Financial support from Caltech and the Dow Next Generation Educator Fund is gratefully acknowledged.

\section{References.}

1. T. J. Penfold, E. Gindensperger, C. Daniel and C. M. Marian, Chem. Rev., 2018, 118, 69757025.

2. K. S. Kjær, T. B. V. Driel, T. C. B. Harlang, K. Kunnus, E. Biasin, K. Ledbetter, R. W. Hartsock, M. E. Reinhard, S. Koroidov, L. Li, M. G. Laursen, F. B. Hansen, P. Vester, M. Christensen, K. Haldrup, M. M. Nielsen, A. O. Dohn, M. I. Pápai, K. B. Møller, P. Chabera, Y. Liu, H. Tatsuno, C. Timm, M. Jarenmark, J. Uhlig, V. Sundstöm, K. Wärnmark, P. Persson, Z. Németh, D. S. Szemes, É. Bajnóczi, G. Vankó, R. Alonso-Mori, J. M. Glownia, S. Nelson, M. Sikorski, D. Sokaras, S. E. Canton, H. T. Lemke and K. J. Gaffney, Chem. Sci., 2019, 10, 5749-5760.

3. H. T. Lemke, K. S. Kjær, R. Hartsock, T. B. van Driel, M. Chollet, J. M. Glownia, S. Song, D. Zhu, E. Pace, S. F. Matar, M. M. Nielsen, M. Benfatto, K. J. Gaffney, E. Collet and M. Cammarata, Nat. Commun., 2017, 8, 15342.

4. R. Monni, G. Auböck, D. Kinschel, K. M. Aziz-Lange, H. B. Gray, A. Vlček and M. Chergui, Chem. Phys. Lett., 2017, 683, 112-120.

5. M. Pižl, B. M. Hunter, G. M. Greetham, M. Towrie, S. Záliš, H. B. Gray and A. Vlček, J. Phys. Chem. A, 2017, 121, 9275-9283.

6. A. Lunghi, F. Totti, S. Sanvito and R. Sessoli, Chem. Sci., 2017, 8, 6051-6059.

7. A. Lunghi, F. Totti, R. Sessoli and S. Sanvito, Nat. Commun., 2017, 8, 14620.

8. D. H. Moseley, S. E. Stavretis, K. Thirunavukkuarasu, M. Ozerov, Y. Cheng, L. L. Daemen, J. Ludwig, Z. Lu, D. Smirnov, C. M. Brown, A. Pandey, A. J. Ramirez-Cuesta, A. C. Lamb, M. Atanasov, E. Bill, F. Neese and Z.-L. Xue, Nat. Commun., 2018, 9, 2572.

9. M. Atanasov and F. Neese, J. Phys. Conf. Ser., 2018, 1148, 012006.

10. P. Udvarhelyi, V. O. Shkolnikov, A. Gali, G. Burkard and A. Pályi, Phys. Rev. B, 2018, 98, 075201.

11. M. L. Goldman, A. Sipahigil, M. W. Doherty, N. Y. Yao, S. D. Bennett, M. Markham, D. J. Twitchen, N. B. Manson, A. Kubanek and M. D. Lukin, Phys. Rev. Lett., 2015, 114, 145502.

12. M. L. Goldman, M. W. Doherty, A. Sipahigil, N. Y. Yao, S. D. Bennett, N. B. Manson, A.

Kubanek and M. D. Lukin, Phys. Rev. B, 2015, 91, 165201.

13. A. Albino, S. Benci, L. Tesi, M. Atzori, R. Torre, S. Sanvito, R. Sessoli and A. Lunghi, Inorg. Chem., 2019, 58, 10260-10268.

14. L. Escalera-Moreno, N. Suaud, A. Gaita-Ariño and E. Coronado, J. Phys. Chem. Lett., 2017, 8, 1695-1700.

15. L. Escalera-Moreno, J. J. Baldoví, A. Gaita-Ariño and E. Coronado, Chem. Sci., 2018, 9, 32653275.

16. V. v. Dobrovitski, G. d. Fuchs, A. I. Falk, C. Santori and D. d. Awschalom, Annu. Rev. Condens. Matter Phys., 2013, 4, 23-50.

17. D. I. Khomskii and G. A. Sawatzky, Solid State Commun., 1997, 102, 87-99.

18. J. Orenstein and A. J. Millis, Science, 2000, 288, 468-474. 
19. A. Lanzara, P. V. Bogdanov, X. J. Zhou, S. A. Kellar, D. L. Feng, E. D. Lu, T. Yoshida, H. Eisaki, A. Fujimori, K. Kishio, J.-I. Shimoyama, T. Noda, S. Uchida, Z. Hussain and Z.-X. Shen, Nature, 2001, 412, 510-514.

20. Y. Tokura and N. Nagaosa, Science, 2000, 288, 462-468.

21. M. Mochizuki, N. Furukawa and N. Nagaosa, Phys. Rev. B, 2011, 84, 144409.

22. T. V. Brinzari, J. T. Haraldsen, P. Chen, Q.-C. Sun, Y. Kim, L.-C. Tung, A. P. Litvinchuk, J. A. Schlueter, D. Smirnov, J. L. Manson, J. Singleton and J. L. Musfeldt, Phys. Rev. Lett., 2013, 111, 047202.

23. M. Rini, R. Tobey, N. Dean, J. Itatani, Y. Tomioka, Y. Tokura, R. W. Schoenlein and A.

Cavalleri, Nature, 2007, 449, 72-74.

24. D. Fausti, R. I. Tobey, N. Dean, S. Kaiser, A. Dienst, M. C. Hoffmann, S. Pyon, T. Takayama, H.

Takagi and A. Cavalleri, Science, 2011, 331, 189-191.

25. M. Först, C. Manzoni, S. Kaiser, Y. Tomioka, Y. Tokura, R. Merlin and A. Cavalleri, Nat. Phys., 2011, 7, 854-856.

26. S. F. Maehrlein, I. Radu, P. Maldonado, A. Paarmann, M. Gensch, A. M. Kalashnikova, R. V.

Pisarev, M. Wolf, P. M. Oppeneer, J. Barker and T. Kampfrath, Sci. Adv., 2018, 4, eaar5164.

27. D. P. DiVincenzo, Fortschritte Phys., 2000, 48, 771-783.

28. J. M. Zadrozny, J. Niklas, O. G. Poluektov and D. E. Freedman, ACS Cent. Sci., 2015, 1, 488492.

29. J. M. Zadrozny, J. Niklas, O. G. Poluektov and D. E. Freedman, J. Am. Chem. Soc., 2014, 136, 15841-15844.

30. M. S. Fataftah, J. M. Zadrozny, S. C. Coste, M. J. Graham, D. M. Rogers and D. E. Freedman, J. Am. Chem. Soc., 2016, 138, 1344-1348.

31. M. S. Fataftah, S. C. Coste, B. Vlaisavljevich, J. M. Zadrozny and D. E. Freedman, Chem. Sci., 2016, 7, 6160-6166.

32. M. J. Graham, J. M. Zadrozny, M. Shiddiq, J. S. Anderson, M. S. Fataftah, S. Hill and D. E. Freedman, J. Am. Chem. Soc., 2014, 136, 7623-7626.

33. M. S. Fataftah, M. D. Krzyaniak, B. Vlaisavljevich, M. R. Wasielewski, J. M. Zadrozny and D.

E. Freedman, Chem. Sci., , DOI:10.1039/C9SC00074G.

34. T. J. Pearson, D. W. Laorenza, M. D. Krzyaniak, M. R. Wasielewski and D. E. Freedman, Dalton Trans., 2018, 47, 11744-11748.

35. J. M. Zadrozny, A. T. Gallagher, T. D. Harris and D. E. Freedman, J. Am. Chem. Soc., 2017, 139, 7089-7094.

36. C.-J. Yu, M. D. Krzyaniak, M. S. Fataftah, M. R. Wasielewski and D. E. Freedman, Chem. Sci., , DOI:10.1039/C8SC04435J.

37. M. Atzori, L. Tesi, E. Morra, M. Chiesa, L. Sorace and R. Sessoli, J. Am. Chem. Soc., 2016, 138, 2154-2157.

38. T. Yamabayashi, M. Atzori, L. Tesi, G. Cosquer, F. Santanni, M.-E. Boulon, E. Morra, S. Benci, R. Torre, M. Chiesa, L. Sorace, R. Sessoli and M. Yamashita, J. Am. Chem. Soc., 2018, 140, 12090-12101.

39. L. Tesi, E. Lucaccini, I. Cimatti, M. Perfetti, M. Mannini, M. Atzori, E. Morra, M. Chiesa, A. Caneschi, L. Sorace and R. Sessoli, Chem. Sci., 2016, 7, 2074-2083.

40. L. Tesi, A. Lunghi, M. Atzori, E. Lucaccini, L. Sorace, F. Totti and R. Sessoli, Dalton Trans., 2016, 45, 16635-16643. 
41. D. Stinghen, M. Atzori, C. M. Fernandes, R. R. Ribeiro, E. L. de Sá, D. F. Back, S. O. K. Giese, D. L. Hughes, G. G. Nunes, E. Morra, M. Chiesa, R. Sessoli and J. F. Soares, Inorg. Chem., 2018, 57, 11393-11403.

42. M. Atzori, A. Chiesa, E. Morra, M. Chiesa, L. Sorace, S. Carretta and R. Sessoli, Chem. Sci., 2018, 9, 6183-6192.

43. M. Atzori, S. Benci, E. Morra, L. Tesi, M. Chiesa, R. Torre, L. Sorace and R. Sessoli, Inorg. Chem., 2018, 57, 731-740.

44. M. Atzori, L. Tesi, S. Benci, A. Lunghi, R. Righini, A. Taschin, R. Torre, L. Sorace and R. Sessoli, J. Am. Chem. Soc., 2017, 139, 4338-4341.

45. A. Ardavan, A. M. Bowen, A. Fernandez, A. J. Fielding, D. Kaminski, F. Moro, C. A. Muryn, M. D. Wise, A. Ruggi, E. J. L. Mclnnes, K. Severin, G. A. Timco, C. R. Timmel, F. Tuna, G. F. S. Whitehead and R. E. P. Winpenny, Npj Quantum Inf., 2015, 1, 15012.

46. E. Garlatti, T. Guidi, S. Ansbro, P. Santini, G. Amoretti, J. Ollivier, H. Mutka, G. Timco, I. J. Vitorica-Yrezabal, G. F. S. Whitehead, R. E. P. Winpenny and S. Carretta, Nat. Commun., 2017, 8, 14543.

47. G. A. Timco, S. Carretta, F. Troiani, F. Tuna, R. J. Pritchard, C. A. Muryn, E. J. L. Mclnnes, A. Ghirri, A. Candini, P. Santini, G. Amoretti, M. Affronte and R. E. P. Winpenny, Nat. Nanotechnol., 2009, 4, 173-178.

48. J. Ferrando-Soria, S. A. Magee, A. Chiesa, S. Carretta, P. Santini, I. J. Vitorica-Yrezabal, F. Tuna, G. F. S. Whitehead, S. Sproules, K. M. Lancaster, A.-L. Barra, G. A. Timco, E. J. L. Mclnnes and R. E. P. Winpenny, Chem, 2016, 1, 727-752.

49. J. McGuire, H. N. Miras, J. P. Donahue, E. Richards and S. Sproules, Chem. - Eur. J., 2018, 24, 17598-17605.

50. K. Bader, D. Dengler, S. Lenz, B. Endeward, S.-D. Jiang, P. Neugebauer and J. van Slageren, Nat. Commun., 2014, 5, 5304.

51. K. N. Shrivastava, Phys. Status Solidi B, 1983, 117, 437-458.

52. K. N. Shrivastava, J. Phys. C Solid State Phys., 1982, 15, 3869-3876.

53. M. Atzori, E. Morra, L. Tesi, A. Albino, M. Chiesa, L. Sorace and R. Sessoli, J. Am. Chem. Soc., 2016, 138, 11234-11244.

54. E. I. Solomon, Comments Inorg. Chem., 1984, 3, 225-320.

55. F. Neese, Wiley Interdiscip. Rev. Comput. Mol. Sci., 2012, 2, 73-78.

56. F. Neese, Wiley Interdiscip. Rev. Comput. Mol. Sci., 2018, 8, e1327.

57. R. K. Szilagyi, M. Metz and E. I. Solomon, J. Phys. Chem. A, 2002, 106, 2994-3007.

58. E. I. Solomon, R. K. Szilagyi, S. DeBeer George and L. Basumallick, Chem. Rev., 2004, 104, 419-458.

59. F. Neese and E. I. Solomon, Inorg. Chem., 1998, 37, 6568-6582.

60. B. Gu and I. Franco, J. Phys. Chem. Lett., 2018, 9, 773-778.

61. R. L. Harlow, W. J. Wells, G. W. Watt and S. H. Simonsen, Inorg. Chem., 1974, 13, 21062111.

62. P. Cassidy and M. A. Hitchman, Inorg. Chem., 1977, 16, 1568-1570.

63. A. A. Gewirth, S. L. Cohen, H. J. Schugar and E. I. Solomon, Inorg. Chem., 1987, 26, 11331146.

64. J. Ferguson, J. Chem. Phys., 1964, 40, 3406-3410. 
65. M. Shiddiq, D. Komijani, Y. Duan, A. Gaita-Ariño, E. Coronado and S. Hill, Nature, 2016, 531, 348-351.

66. G. Wolfowicz, A. M. Tyryshkin, R. E. George, H. Riemann, N. V. Abrosimov, P. Becker, H.-J. Pohl, M. L. W. Thewalt, S. A. Lyon and J. J. L. Morton, Nat. Nanotechnol., 2013, 8, 561-564. 67. G. Wolfowicz, S. Simmons, A. M. Tyryshkin, R. E. George, H. Riemann, N. V. Abrosimov, P. Becker, H.-J. Pohl, S. A. Lyon, M. L. W. Thewalt and J. J. L. Morton, Phys. Rev. B, 2012, 86, 245301.

68. S. Ghosh, S. Datta, L. Friend, S. Cardona-Serra, A. Gaita-Ariño, E. Coronado and S. Hill, Dalton Trans., 2012, 41, 13697-13704.

69. A. J. Fielding, S. Fox, G. L. Millhauser, M. Chattopadhyay, P. M. H. Kroneck, G. Fritz, G. R. Eaton and S. S. Eaton, J. Magn. Reson., 2006, 179, 92-104.

70. J. M. Flowers, J. C. Hempel, W. E. Hatfield and H. H. Dearman, J. Chem. Phys., 1973, 58, 1479-1486.

71. D. Collison, B. Gahan, C. D. Garner and F. E. Mabbs, J. Chem. Soc. Dalton Trans., 1980, 667674.

72. C. Finazzo, C. Calle, S. Stoll, S. V. Doorslaer and A. Schweiger, Phys. Chem. Chem. Phys., 2006, 8, 1942-1953.

73. K. Mrkvová, J. Kameníček, Z. Šindelář, L. Kvítek, J. Mrozinski, M. Nahorska and Z. Žák,

Transit. Met. Chem., 2004, 29, 238-244.

74. M. Warner, S. Din, I. S. Tupitsyn, G. W. Morley, A. M. Stoneham, J. A. Gardener, Z. Wu, A. J.

Fisher, S. Heutz, C. W. M. Kay and G. Aeppli, Nature, 2013, 503, 504-508.

75. J. M. Assour, J. Goldmacher and S. E. Harrison, J. Chem. Phys., 1965, 43, 159-165.

76. A. Noll, S. Rabe and U. Müller, Z. Für Naturforschung B, 1999, 54, 591-596.

77. V. Nagarajan, B. Müller, O. Storcheva, K. Köhler and A. Pöppl, Res. Chem. Intermed., 2007, 33, 705-724.

78. B. L. Vallee and R. J. Williams, Proc. Natl. Acad. Sci., 1968, 59, 498-505.

79. B. G. Malmström, Eur. J. Biochem., 1994, 223, 711-718.

80. R. J. P. Williams, Eur. J. Biochem., 1995, 234, 363-381.

81. H. B. Gray, B. G. Malmström and R. J. P. Williams, JBIC J. Biol. Inorg. Chem., 2000, 5, 551559.

82. S. Ghosh, X. Xie, A. Dey, Y. Sun, C. P. Scholes and E. I. Solomon, Proc. Natl. Acad. Sci., 2009, 106, 4969-4974.

83. M.-L. Tsai, R. G. Hadt, N. M. Marshall, T. D. Wilson, Y. Lu and E. I. Solomon, Proc. Natl. Acad. Sci., 2013, 110, 14658-14663.

84. M. W. Mara, R. G. Hadt, M. E. Reinhard, T. Kroll, H. Lim, R. W. Hartsock, R. Alonso-Mori, M. Chollet, J. M. Glownia, S. Nelson, D. Sokaras, K. Kunnus, K. O. Hodgson, B. Hedman, U. Bergmann, K. J. Gaffney and E. I. Solomon, Science, 2017, 356, 1276-1280.

85. L. Kohler, R. G. Hadt, D. Hayes, L. X. Chen and K. L. Mulfort, Dalton Trans., 2017, 46, 1308813100.

86. B. Dicke, A. Hoffmann, J. Stanek, M. S. Rampp, B. Grimm-Lebsanft, F. Biebl, D. Rukser, B.

Maerz, D. Göries, M. Naumova, M. Biednov, G. Neuber, A. Wetzel, S. M. Hofmann, P. Roedig, A. Meents, J. Bielecki, J. Andreasson, K. R. Beyerlein, H. N. Chapman, C. Bressler, W. Zinth, M. Rübhausen and S. Herres-Pawlis, Nat. Chem., 2018, 10, 355-362.

87. J. Stanek, A. Hoffmann and S. Herres-Pawlis, Coord. Chem. Rev., 2018, 365, 103-121. 
88. B. E. R. Snyder, P. Vanelderen, M. L. Bols, S. D. Hallaert, L. H. Böttger, L. Ungur, K. Pierloot, R. A. Schoonheydt, B. F. Sels and E. I. Solomon, Nature, 2016, 536, 317-321.

89. P. Comba, S. Fukuzumi, C. Koke, B. Martin, A.-M. Löhr and J. Straub, Angew. Chem. Int. Ed., 2016, 55, 11129-11133.

90. Y.-I. Sohn, S. Meesala, B. Pingault, H. A. Atikian, J. Holzgrafe, M. Gündoğan, C. Stavrakas, M. J. Stanley, A. Sipahigil, J. Choi, M. Zhang, J. L. Pacheco, J. Abraham, E. Bielejec, M. D. Lukin, M. Atatüre and M. Lončar, Nat. Commun., 2018, 9, 1-6. 